\title{
LUCES Y SOMBRAS EN TORNO A LA REGULACIÓN JURÍDICA DE LA FILIACIÓN EN CUBA
}

\author{
"Un hijo es el mejor premio que un \\ hombre puede recibir sobre la tierra" \\ "Los hijos son urnas de bálsamo" \\ J. MARTI
}

\author{
LEONARDO PÉREZ GALLARDO* \\ Universidad de La Habana
}

\begin{abstract}
RESUMEN: El presente trabajo tiene por finalidad realizar un exhaustivo análisis sobre la regulación de la filiación en Cuba. Se hace en él un examen crítico de su sistema, en conjunto con una comparación de la actual legislación con el Anteproyecto de Código de Familia. La filiación en el ámbito legal cubano no es de las instituciones jurídicas que ofrezcan un panorama enriquecedor, dinámico y moderno. Las ideas que intenta reflejar el autor van dirigidas a demostrar ese estado. Este es al menos asimétrico, lo que básicamente se ve en la regulación de las acciones filiatorias, consecuencia de la fragmentación del soporte normativo en que se asientan los pilares legales de la figura.
\end{abstract}

Palabras clave: Filiación, acciones filiatorias, reconocimiento.

ABSTRACT: This essay is meant to analyze the regulation of filiation in Cuba. A critical examination of this filiation system is exposed with a comparison of today's draft Family Code legislation. Filiation in the Cuban legal system is not a dynamic, modern, and enriching institution. The proponent's objective is to reflect this existing condition in the Cuban legal system. The regulation of filiation actions in the Cuban legal system is unproportional, and a direct consequence of the normative fragmentation based upon the Cuban legal system.

Key words: Filiation, fliation actions, recognition.

\section{EL NO DISCRIMEN DE LOS HIJOS EN RAZÓN DE SU FILIACIÓN. SU CONSAGRACIÓN COMO PRINCIPIO CONSTITUCIONAL}

La Constitución de la República de Cuba de 1976, modificada luego en 1992 y en el 2002, reserva uno de los artículos contenidos en el capítulo concerniente a la familia al reconocimiento del principio de no discriminación de los hijos en razón de la filiación, es decir, la igualdad en el tratamiento legal de los hijos, así sea su filiación. Ello, obedece a un largo proceso de evolución normativa que tuvo su antecedente más importante en la Constitución de 1940, que en su artículo 44, tercer párrafo, llegó a formular: "Queda abolida toda calificación sobre la naturaleza de la filiación. No se consignará declaración alguna diferenciando los nacimientos, ni sobre el estado civil de los padres, en las actas de inscripción de aquéllos, ni en

Notario y Profesor Titular de Derecho Civil de la Facultad de Derecho. Universidad de La Habana. 
ningún atestado, partida de bautismo o certificación referente a la filiación”. Constitución que, para la fecha de su promulgación, constituyó una las más progresistas del mundo, al recoger en su preceptiva un principio de dimensiones y alcances no solo jurídicos, sino éticos, de la talla del que está contenido en dicho precepto. Empero, fue lamentable que el Código Civil español, vigente en Cuba a la fecha, no se hubiera atemperado al precepto constitucional. Ello, a pesar del trabajo legislativo realizado a ese fin, que tristemente no cristalizará en la modificación tanto del Código ${ }^{1}$, como de la Ley del Registro del Estado Civil y otras disposiciones normativas que siguieron marcando la diferencia de la prole, en razón de su origen filiatorio.

En este principio tiene su sede uno de los ejes cardinales del Derecho de Familia en Cuba y que fue motivo durante décadas de un tratamiento vejaminoso de los hijos, extremadamente injusto, dado que el actuar de los padres no debe nunca ser pechado a los hijos. Durante décadas, el esquema dogmático de la clasificación de los hijos en legítimos e ilegítimos y dentro de estos, a los naturales y no naturales, y a su vez, en los no naturales a los espurios, sacrílegos, adulterinos e incestuosos, no solo era objeto de estudio por la doctrina científica, sino de regulación jurídica con un tratamiento dispar que motivaba una abismal diferencia en el tratamiento de los derechos, sobre todo patrimoniales, de los hijos, además del estigma social que representaba.

La Constitución de 1976 no solo llevó al plexo normativo el principio de no discriminación de los hijos por razón de la filiación, sino que este principio luego tuvo un desarrollo normativo, sobre todo en el Código de Familia ${ }^{2}$, en la Ley del Registro del Estado Civil y en el Código Civil, de modo que a la tutela constitucional responde el Derecho sustantivo infraconstitucional. En este sentido, como apunta la profesora MESA CASTILLO: "El matrimonio deja de enfatizarse como la vía fundamental de legitimación de la paternidad y esta se hace descansar, fundamentalmente, en el reconocimiento e inscripción del hijo, aunque no mediare matrimonio entre los padres" 3 .

\footnotetext{
1 Nos da cuenta el profesor MARTínez GIRALT, Félix. Sucesiones (copia de clases), Facultad de Derecho, Universidad de La Habana, Curso 1945-46, que al efecto fue creada una comisión oficial, integrada por los profesores, doctores, Alberto BLANCO, Eduardo Le RIVEREND y Antonio DíAZ PAIRÓ, comisión a la que le fue confiada la labor de redactar las modificaciones de los preceptos del Código Civil a los fines de adaptarlo a los cambios constitucionales. Proyecto que solo quedó en ello, dado que fue enviado por el Poder Ejecutivo al Congreso en el año 1940, sin que nunca hubiese sido discutido.

2 Gómez Treto, Raúl. “¡Hacia un nuevo Código de Familia?”, en: Revista Cubana de Derecho, UNJC. Cuba, Habana: Ediciones Cubanas, No. 29, enero-junio 2007. p. 219: "En relación con los hijos, nuestro Código de Familia hizo la justicia de igualarlos a todos en sus relaciones jurídicas con los demás miembros de la familia y entre sí, borrando aquella injuriosa distinción entre los legítimos y los ilegítimos que cargaba sobre ellos las consecuencias de los actos de sus padres".

3 Mesa Castillo, Olga. "Regulación normativa de la filiación en el Estado cubano", en: Temas de Derecho de Familia, pp. 69-70. La Habana, Cuba: Colectivo de autores, Félix Varela. 2001.
} 


\section{LA FILIACIÓN EN EL ORDENAMIENTO JURÍDICO FAMILIAR CUBANO: UN NECESARIO ESBOZO DE LA FIGURA}

La filiación como relación jurídica que se crea entre personas que, en principio, están vinculadas por el hecho biológico de la procreación, tiene un alcance muy superior, pues sin negar la trascendencia del dato biológico, para fijarla y determinarla, este no es esencial. Si bien la filiación, como ha expresado nuestra Sala de lo Civil y de lo Administrativo del Tribunal Supremo en su Sentencia No. 222 de 31 de julio del 2009, único Considerando (ponente Acosta Ricart) "es la forma en que desde el punto de vista legal se concreta el hecho de la concepción biológica”, la adopción genera igualmente una relación filiatoria entre el adoptante y el adoptado, a pesar de que no pueda hablarse en este caso de que técnicamente haya existido una procreación, ni tampoco cabría hablar entonces, de procreantes y procreados, en tanto la intención y voluntad de ser padre ha primado sobre el dato biológico de la reproducción sexual de los organismos de la especie humana. Como expresa Lacruz Berdejo, "no tiene por qué sorprender la no coincidencia de la relación jurídica con la relación biológica de filiación, precisamente la relación jurídica filiatoria es mucho más rica que la relación biológica, en tanto categoría jurídica y social, en la que se integran elementos afectivos, volitivos, sociales, formales, etcétera" ${ }^{4}$.

La filiación en el ámbito legal cubano paradójicamente no es de las instituciones jurídicas que ofrezcan un panorama enriquecedor, dinámico y moderno. Las ideas que intento reflejar van dirigidas a demostrar ese estado, si bien no caótico, sí al menos asimétrico de regulación de las acciones filiatorias, motivado por la fragmentación del soporte normativo en que se asientan los pilares legales de la figura, amén de la orfandad doctrinaria de la que ha sido objeto en las últimas décadas en nuestro país. Como también expresa la profesora Mesa Castillo, la necesidad de perfeccionar y de actualizar el Derecho de Familia cubano es "sensiblemente imprescindible para la regulación normativa de la filiación"5.

\subsection{El TRÍPTICO LEGAL QUE AMPARA SU REGULACIÓN}

La regulación jurídica de la filiación en Cuba es parca, fragmentada y antinómica. La parquedad viene dada porque el legislador ha regulado la filiación a medias, dejando un sinnúmero de lagunas que resultan muy difícil de completar, por mucha obra de orfebrería que puedan hacer los jueces en sus sentencias. La fragmentación se produce con la promulgación de la Ley del Registro del Estado Civil, en 1985, y con su Reglamento, al derogar la primera

\footnotetext{
4 Rivero Hernández, Francisco. Elementos de Derecho Civil IV - Derecho de Familia. Vol. 2 -3a Edición- Barcelona, España: Editorial Bosch, 1989, p. 25.

5 Mesa Castillo, Olga, op. cit. (n. 3), pp. 75-76.
} 
de varios preceptos contenidos en el Código de Familia, cuerpo normativo al cual le viene dado por esencia la regulación de esta institución jurídica de naturaleza eminentemente sustantiva, lo que agravó la situación, pues empeoró la escuálida regulación jurídica de esta figura, construyendo un tríptico legal, a saber: Código de Familia - Ley del Registro del Estado Civil - Reglamento de dicha ley, en el que se tejen las redes de la regulación de la filiación en $\mathrm{Cuba}^{6}$ y precisamente ello conduce al carácter antinómico de la regulación pues la sumatoria de estas normas jurídicas no dan un producto acabado, sino macerado, con preceptos que se superponen, repitiéndose $(v \cdot g r$, artículo 6, segundo y tercer párrafos, del Código de Familia y 62 de la Ley del Registro del Estado Civil, artículos 84 y 85 del Reglamento de la Ley del Registro del Estado Civil en relación con el artículo 48 de la Ley, artículo 86 del mismo Re-

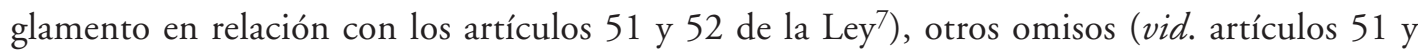
52 de la Ley del Registro del Estado Civil al regular acciones filiatorias que luego no tienen un verdadero amparo legal), y otros con una terminología inapropiada que llevan a la confusión de los operadores del Derecho (vid. artículo 77 del Código de Familia que expresamente dispone "acción para reclamar el reconocimiento", cuando se trata de la acción reclamatoria de filiación; artículo 80 del propio Código que alude a la impugnación del reconocimiento, cuando en realidad lo que se impugna es la filiación; artículo 47 de la Ley del Registro del Estado Civil que da a entender que la inscripción del nacimiento de los hijos de padres no unidos en matrimonio formalizado o reconocido judicialmente la hacen los padres conjuntamente o uno de ellos, en vez del oficial encargado del Registro del Estado Civil).

\section{EL PRINCIPIO DE LA LIBRE INVESTIGACIÓN DE LA PATERNIDAD Y DE LA MATERNIDAD}

Explícitamente, como pretende el Anteproyecto de Código de Familia sea incluido en su preceptiva, el citado principio de la libre investigación de la paternidad y de la ma-

\footnotetext{
Gómez Treto, Raúl, op. cit. (n. 2), pp. 222-223. Para quien, en criterio que no comparto, intenta justificar lo injustificable, con un argumento, a mi juicio, nada convincente: "El Código de Familia sufrió una última modificación en virtud de la (...) Ley del Registro del Estado Civil, No. 51, de 15 de julio de 1985. En esta disposición legal se sustrajeron, mediante derogación, varios artículos del Código de Familia que más que normas o preceptos sustantivos -como correspondía haber hecho desde el inicio-involucraban normas adjetivas de carácter registral administrativo y que más propiamente debian incluirse en dicha nueva Ley del Registro del Estado Civil. Este quebrantamiento de la sistemática legislativa no fue producto del descuido, la ignorancia ni la negligencia, sino resultado de que a la hora de elaborar el Código de Familia se sabía que habia ya que reestructurar los Registros del Estado Civil, pero se sabia también que no era posible acometer esa tarea en aquel momento; de ahi que se optó por incluir en el Código preceptos atinentes al Registro que tácitamente modificaban a la vieja ley registral española, obviándose así intentar su actualización expresa mediante disposiciones finales derogatorias o modificativas de preceptos concretos de ella que, en todo caso, significarían solamente un remiendo y no la reestructuración total que se requería".

7 Rosabal Lam, Carmen. Disquisiciones teóricas en torno a la filiación en Cuba. Memoria de prueba (diplomado), profesora guía Dra. Olga Mesa Castillo. La Habana, Cuba: Facultad de Derecho, Universidad de La Habana, 2000, pp. 66-68.
} 
ternidad $^{8}$, no lo recoge el ordenamiento jurídico cubano. Empero, cuando en el cuarto y último párrafo del artículo 37 de la Constitución se deja esclarecido que: "El Estado garantiza mediante los procedimientos legales adecuados la determinación y el reconocimiento de la paternidad", además de asumir el Estado la responsabilidad de que en el orden legal se vertebren los procedimientos atinados para la determinación y el reconocimiento de la paternidad, hoy utilizando un lenguaje de género, diríase también de la maternidad, no cabe dudas que para esa determinación, cuando hay conflictos de paternidad o de maternidad, ya sea porque se intente el reconocimiento de la prole por más de un progenitor, o porque se pretenda impugnar la filiación reconocida por un tercero por quien se crea el verdadero padre o madre del hijo reconocido, es necesario acudir a las técnicas de investigación genéticas que auxiliarían al tribunal en la solución del caso, razón por la cual hay un reconocimiento implícito del mencionado principio.

El Derecho cubano, en este orden, siguiendo el postulado constitucional, no pone cortapisas a la libre investigación de la paternidad y de la maternidad, ya se ejercite la acción filiatoria contra personas casadas, sin que la reputación, las buenas costumbres, la moral, el orden público, el honor de la familia, el derecho a la intimidad, a la vida privada, sean límites impuestos para este tipo de investigación? 9 A tono con el artículo 7.1 de la Convención Internacional sobre los derechos del Niño, el Estado cubano contribuye a que los niños tengan derecho "en la medida de lo posible, a conocer a sus padres". Por supuesto, ello en el más estricto respecto a la dignidad e integridad de la persona, dígase progenitores.

Lamentablemente, lo que ha sucedido es que los procedimientos legales adecuados hoy no están a tono con la dinámica de la vida actual, con el desarrollo tecnológico y de las ciencias médicas y biológicas. Las normas infraconstitucionales no dan la respuesta óptima al pulso dado por la Constitución. La carencia de un procedimiento familiar y de los tribunales de familia ${ }^{10}$, amén de la legislación familiar anclada en los años 70 del siglo pasado, hacen difícil, si bien no imposible, la búsqueda de esa verdad que todo proceso filiatorio persigue.

\footnotetext{
$8 \quad$ En efecto, el artículo 83 de dicho Anteproyecto dispone: "En todo proceso de filiación puede practicarse la investigación de la paternidad y la maternidad mediante toda clase de pruebas", incluidas por supuesto, las pruebas biológicas, siempre que las circunstancias económicas del país, permitan su empleo, lo que hoy día resulta un verdadero quebradero de cabeza, en tanto $v$. $g r$., la prueba de $\mathrm{ADN}$ a la cual recurren una y otra vez las partes contendientes de un proceso filiatorio, resulta denegada, a muy pesar del tribunal juzgador, por no contar el país con los recursos necesarios para hacer frente al pago de reactivos imprescindibles para la realización de la prueba.

9 Parra BeníteZ, Jorge. La filiación en Derecho de Familia. Bogotá, Colombia: Leyer, 2008, pp. 50-51. Al hacer un estudio comparado en el ámbito constitucional del derecho de filiación, resalta la Constitución cubana, en tanto, esta "se detiene un poco más en el contenido material de algunos derechos de los hijos, pero sobresale por su énfasis en el principio de igualdad (...) y en la investigación de la filiación mediante procedimientos adecuados".

10 Sobre la fundamentación de la necesidad de una jurisdicción familiar en Cuba: ÁLVAREZ TORRES, Osvaldo. "El procedimiento familiar en Cuba. Una necesidad impostergable”, en: Revista Cubana de Derecho, UNJC. No. 18. Cuba, Habana: Ediciones Cubanas, julio-diciembre, 2001. pp. 66-79.
} 


\section{LAS PRESUNCIONES FILIATORIAS}

No distingue el Derecho cubano la filiación extramatrimonial de la filiación matrimonial, ni siquiera se utilizan estos términos, si bien, no cabe duda que el modo de determinación de la filiación, es distinto si la procreación tiene lugar entre personas que tienen constituido un matrimonio o reconocen los efectos jurídicos de su unión matrimonial no formalizada por la vía extrajudicial o la judicial (vid. artículos 2 y 18 del Código de Familia, 71 de la Ley del Registro del Estado Civil y 79 de la Ley de las Notarías Estatales) .

Las presunciones constituyen un modo de determinación legal de la filiación y están reguladas en los artículos 74 al 76 del Código de Familia. Como apunta Guzmán Ávalos "La presunción es un hecho desconocido, que se deduce o induce, de otros hechos conocidos con los que guarda relación" 11 .

\subsection{LAS PRESUNCIONES DE FILIACIÓN MATRIMONIAL}

En este sentido, el artículo 74 regula como presunción iuris tantum de filiación el considerar como hijos de las personas que están unidas en matrimonio, los que nazcan durante la vida matrimonial. Mientras el matrimonio no se extinga, siguiendo el principio "Pater est quem nuptiae demostrant", o lo que es lo mismo, se presume que el padre es el marido de la madre, basado en todo caso, en la obligación de convivencia y fidelidad de los cónyuges, establecida esta en el artículo 24, párrafo primero del Código de Familia, a cuyo tenor se impone a los cónyuges el deber de "vivir juntos, guardarse la lealtad, la consideración y el respeto debidos". La presunción tiene su ratio en la naturaleza de las relaciones conyugales o sexuales, infiriéndose que el marido tiene relaciones sexuales con su esposa y, en consecuencia, el hijo concebido durante ese tempus, es de él.

A juicio de alguna autora, la expresión "vida matrimonial", "alude al matrimonio formalizado o reconocido judicialmente, por tanto, para alegarla en este último supuesto es imprescindible que en el momento de su apreciación ya exista sentencia judicial que reconozca el matrimonio; pues aunque esa declaración del tribunal tiene efectos retroactivos, dicha unión matrimonial no surtirá efectos legales hasta que no se reconozca de conformidad con lo establecido en el segundo párrafo del artículo 2 del propio Código de Familia"12. En tal sentido, cabría entender que la presunción filiatoria contenida en el inciso 1 del artículo 74 del Código de Familia es de alcance general, sin distinguir tipo de matrimonio, sea el formalizado o el re-

11 GuZmán Ávalos, Aníbal. La filiación en los umbrales del siglo XXI. D.F, México: Porrúa, 2005, p. 35.

12 Aldaya Bayón, Rita María. El régimen jurídico de la filiación. Tesis (maestría en Derecho de Familia). La Habana, Cuba: Facultad de Derecho, Universidad de La Habana, 2007, p. 29. 
conocido judicialmente ${ }^{13}$. Si se quisiera alegar en un supuesto de reconocimiento judicial de matrimonio no formalizado, entonces, sería necesario que la unión matrimonial ya hubiere estado reconocida judicialmente, de modo que la sentencia que declarara con lugar la demanda interpuesta, estuviere firme y practicado el asiento de inscripción del matrimonio en el Registro del Estado Civil. A tono con esta presunción, la Ley del Registro del Estado Civil en su artículo 45 habilita a que, en caso de que exista una unión matrimonial reconocida judicialmente, la declaración de paternidad o maternidad hecha por uno de los padres ${ }^{14}$, surtirá efectos jurídicos para el otro, precisamente en razón de la presunción reconocida en el artículo 74.1 del Código de Familia.

No obstante, hay que tener muy en cuenta que el legislador hace descansar el hecho presumido, en el hecho base, que en el caso, es la existencia de la vida matrimonial. Término con el cual se va más allá del matrimonio como acto formal. La presunción se sustenta en la cohabitación marital, en la vida afectiva y sexual de la pareja, en la fidelidad y respeto de los cónyuges, de modo que la ausencia de estos pudieran resultar serios argumentos para destruir la presunción iuris tantum de paternidad. No obstante, la presunción en sí misma supone un favor iuris a favor de los hijos, al concedérseles el status filii a estos, sin que importe mucho la coincidencia del dato biológico con el lazo jurídico. Como presunción, opera automáticamente desde que nazca el hijo de una mujer casada.

A diferencia de otros ordenamientos jurídicos, tampoco se hace distinción si el hijo fue concebido antes o después del matrimonio. El Código de Familia cubano no establece términos probabilísticos del momento en que tuvo lugar la concepción. Lo que trasciende a los efectos de esta presunción filiatoria es que el nacimiento haya tenido lugar durante la vida matrimonial. De este modo, aunque sin trascendencia para el Derecho en cuanto a la clasificación per se, serán matrimoniales los hijos habidos dentro del matrimonio, sin que importe el momento de la concepción. Se entiende que el marido ha admitido el embarazo y asumido la paternidad. Por ello la presunción opera para "las personas unidas en matrimonio", o lo que es lo mismo, para los cónyuges, sin hacer distinción del uno o del otro.

La segunda presunción filiatoria viene reconocida en el inciso 2 del artículo 74. A su tenor, también se presume la filiación de los hijos nacidos dentro de los trescientos días siguientes a la fecha de extinción del matrimonio -o de nulidad diría yo, en buena técnica jurídica, pues la nulidad no es un supuesto de extinción matrimonial- ${ }^{15}$. No se extingue lo que

\footnotetext{
13 El Anteproyecto de Código de Familia, en su última versión de 21 de mayo del 2008, en su artículo 88 inciso 3, señala: "Los nacidos durante el período que el tribunal declare judicialmente reconocida la unión no formalizada de la madre y el padre".

14 Si bien, indebidamente el legislador hace referencia a la inscripción del nacimiento, lo cual en todo caso corresponderá al oficial del Registro del Estado Civil y no así al padre o a la madre, que expresarán la declaración de paternidad o maternidad, según corresponda, que sirve de fuente para el asiento de inscripción registral.

15 Así se corrige, por fortuna, en el Anteproyecto de Código de Familia, en el artículo 88.2.
} 
no ha nacido para el Derecho. Se trata del plazo máximo que pudiera durar un embarazo. Por lo tanto, transcurrido este, el ex marido puede negar o desconocer la filiación. Al Derecho le interesa, no obstante, extender la presunción de paternidad, más allá incluso de la existencia del matrimonio, pues ahora sí se entiende una presunción de concepción matrimonial, o sea, se considera que la concepción tuvo lugar durante el matrimonio. A diferencia de la presunción anterior en esta, es la concepción la que ha tenido lugar dentro del matrimonio y el nacimiento, extinguido el matrimonio, pero trayendo causa de este. En una y otra presunción, el legislador cubano, no busca en lo absoluto la legitimidad o no el hijo, sino su protección, en sentido de favorecerle con la existencia de un padre, si bien esta idea resulta discutible. De ahí ese afán del legislador de facilitar la determinación de la filiación, aun a costa de que no haya coincidencia entre la verdad formal y la material, a pesar de que el padre sea tan solo presumido y nada más, aunque como tal conste en el asiento de inscripción del nacimiento.

Para evitar la turbatio sanguinis, se impone como requisito formal en el artículo 6, segundo párrafo del Código de Familia, en relación con el artículo 62 de la Ley del Registro del Estado Civil, que se aporte por la mujer que quiere formalizar un nuevo matrimonio, certificación expedida por un centro asistencial, acreditativa de su posible estado de gravidez o no. Obsérvese que de acuerdo con el contenido de ambas normas, que se reiteran por cierto, no se trata de una prohibición legal para contraer matrimonio, sino de una cautela legal para evitar confusión de paternidades. Así, si el hijo nace durante los primeros trescientos días de extinguido o anulado el primer matrimonio, se presume, salvo prueba en contrario, hijo del primer esposo, si nace después, cesa el efecto de la presunción, y si ese después se hace corresponder a un momento posterior al segundo matrimonio, operaría la presunción contenida en el inciso 1 del artículo 74 del Código de Familia en relación con el segundo esposo.

Se trata de que el notario o el registrador ante el cual se formalice el matrimonio, en cumplimiento del Derecho positivo, exija el citado documento que se adjuntará al expediente matrimonial, y que como dispone el artículo 62 de la Ley del Registro del Estado Civil, aun siendo positivo, no interrumpirá los trámites matrimoniales, sino tan solo operará la presunción iuris tantum de paternidad respecto del ex cónyuge (vid. artículo 6, tercer párrafo, del Código de Familia). Constituye un requisito formal auxiliar de este modo legal de determinación de la paternidad.

Si bien nada disponen las normas vigentes, con un sentido de racionalidad, el requisito no se predicará respecto de las mujeres que, por su edad, no están aptas físicamente para procrear, ni de aquellas que en ese breve período, pretenden formalizar matrimonio con el mismo cónyuge, pues en este caso, la previsión de la turbatio sanguinis, no tiene lugar, razón por la cual el requisito de la certificación médica resultaría insostenible ${ }^{16}$.

16 Sobre el tema se pronuncia la profesora MESA CASTILLO, Olga, "La formalización del matrimonio ante notario y registrador del estado civil". En: Pérez Gallardo, Leonardo B. y Lora-TAmayo Rodríguez, Isidoro (coord.)Derecho Notarial, Tomo III. La Habana, Cuba: Félix Varela, 2008, pp. 204-205. 
Es bueno aclarar que, tratándose de un matrimonio extinguido por declaración judicial de presunción de muerte del esposo, hay que tener muy en cuenta que, el día presuntivo en que acaeció la muerte es el dispuesto en la resolución judicial, conforme con los medios de prueba aportados, o sea, en atención a lo que ha sido probado ante el tribunal, de modo que los efectos de la resolución judicial se retrotraen a esa fecha. Es la posición que adopta el artículo 36.2 del Código Civil cubano. A mi juicio, la más atinada. Lo contrario, partiría de un presupuesto injusto. Ahora bien, aun asumiendo esta tesis, el legislador establece como regla normativa, a tenerse en cuenta por el juzgador en su resolución judicial, que tal retroacción se hace con respecto "al momento en que se produjo el acontecimiento que hizo presumir la muerte o se tuvieron las últimas noticias del desaparecido", según el tenor literal del artículo 36.2. Con ello, se prevén ambos supuestos: Declaración judicial de presunción de muerte en condiciones extraordinarias y en condiciones ordinarias. Para la primera, el día se fijará al momento en que el acontecimiento tuvo lugar, para la segunda, aquel en que se tuvieron las últimas noticias de la existencia con vida del desaparecido. Hasta esa fecha, rige la presunción de vida, más allá, la de muerte. Ergo, si quien pretende formalizar matrimonio es la viuda de una persona que se ha declarado presuntamente muerta, retrotrayéndose la fecha a aquella fijada por la sentencia judicial, no tendría nunca que acreditar bajo certificación médica su estado de gravidez, dado que la presunción de filiación nunca involucraría al presuntamente muerto por razones lógicas de tiempo, ya que esta presunción tiene un radio temporal de trescientos días, y dado que la viuda no estará en condiciones de contraer un nuevo matrimonio hasta tanto no se haga firme la resolución judicial que declara la presunción judicial de muerte del marido y por ello adquiera la viudez, si además se conoce que para promover este proceso el Derecho exige el transcurso de ciertos plazos, que se extienden a tres años cuando la muerte se presume acaecida en circunstancias ordinarias y a un año en circunstancias extraordinarias ${ }^{17}$, la lógica nos indicaría la imposibilidad temporal de que la viuda en este contexto pueda haber tenido acceso carnal con el presuntamente muerto en un período menor de trescientos días. Por ello, el alcance de la presunción de paternidad contenida en el artículo 74.2 del Código de Familia, solo abarca los supuestos de extinción del matrimonio, ya sea por divorcio o por fallecimiento del cónyuge y el caso de la nulidad matrimonial.

\footnotetext{
17 Como ya he explicado en otras ocasiones, PÉrEZ GALLARDO, Leonardo B., "La declaración judicial de presunción de muerte: una aproximación tópica a su estudio” pp. 59-114. En: La regulación jurídica de la muerte en Iberoamérica, con particular referencia al Derecho cubano. Bogotá, Colombia: Temis; México: Ubijus; Madrid, España: Reus; Buenos Aires, Argentina: Zavalia, 2009. Los plazos exigidos ex lege para interesar judicialmente la declaración de muerte presunta, no constituyen un plus de esta figura, sino forman parte de su propio contenido. El transcurso del tiempo, desde que se tuvieron las últimas noticias del desaparecido o desde que sobrevino el acontecimiento notorio en el que supuestamente tuvo lugar el hecho luctuoso, es un elemento que refuerza per se la presunción de muerte, ese estado de incerteza sobre la existencia de una persona prolongado en el tiempo, hace que cobre mayor sustantividad la probabilidad de muerte. Por ello, el discurrir de tales plazos es un presupuesto para el ejercicio del derecho por quienes estén legitimados para interesar del órgano judicial la declaración judicial de presunción de muerte, pero en modo alguno puede confundirse con los plazos de prescripción y de caducidad consagrados en los artículos 112 al 126 del Código Civil.
} 


\subsection{LAS PRESUNCIONES FILIATORIAS DE PATERNIDAD EXTRAMATRIMONIAL}

En relación con las presunciones de paternidad reguladas en el artículo 75, aunque el Código de Familia nada regula expresamente, son aplicables a supuestos de paternidad extramatrimonial, pues si esta es habida durante la vida matrimonial, resultan atinentes la presunciones contenidas en el artículo 74. El Derecho de Familia cubano se apoya de las presunciones contenidas en este precepto a los efectos de determinar la filiación paterna.

La primera de las presunciones atañe a la declaración paterna en documento indubitado, tal declaración no constituye, por supuesto, prueba directa de la filiación, es el hecho base, del cual se colige el hecho presumido que es la propia filiación. En primer orden, el carácter indubitado del documento no es sinónimo de documento notarial, si bien este goza de una fuerte presunción de veracidad, exactitud, legitimidad, y autenticidad interna y externa, con los efectos que a las declaraciones de voluntad contenidas en él les confiere entre partes el artículo 294 de la Ley de Procedimiento Civil, Administrativo, Laboral y Económico (en lo adelante LPCALE), no se trata de una declaración expresa de voluntad. Si así fuere, estaríamos en presencia de un reconocimiento voluntario contenido en documento público notarial. Lo que el legislador da realce es a la declaración de voluntad del padre, que pudiera tener carácter meramente enunciativo y a la naturaleza indubitada del documento en que se contiene, de ahí que pudiera hablarse de una carta familiar o cualquier declaración jurada ante funcionario público o administrativo, de la cual cabría colegirse, por vía de inducción, el reconocimiento paterno de la filiación, la admisión de la condición de padre. La naturaleza indubitada apunta a la existencia de la firma del progenitor, bajo la fe pública notarial o administrativa, o con la intervención de algún oficial público o la adveración de un documento privado por vía judicial.

Según el dictado literal del inciso 2 del artículo 75, también se presumirá la paternidad en supuestos de relaciones extramatrimoniales, cuando las relaciones maritales del padre con la madre hayan sido notorias en el período en que pudo tener lugar la concepción. Llama la atención la amplitud con la que se formula el precepto. En primer orden, resulta preciso definir adecuadamente qué se entiende por relaciones notorias. En el ámbito notarial, apunta Zavala que "podemos relacionar a lo notorio, como aquello que es público y sabido por todos, con una presunción que es considerar público a lo notorio y una falsedad -al margen de la presunción- pensar que lo notorio sea conocido por todos"18. Otros autores como Ávila Álvarez entienden por hechos notorios "aquellos conocidos por la generalidad de las personas que se encuentran en una relación más directa o próxima con el hecho o con sus consecuencias, o pertenecen al entorno social o económico de aquella a quien el hecho afecta"19. En esta

\footnotetext{
18 Zavala, Gastón A. Declaratoria extrajudicial de herederos. La intervención notarial. Buenos Aires, Argentina: Ad Hoc, 2007, p. 132.

19 Ávila Álvarez, Pedro. Derecho Notarial. -7a Edición- Barcelona, España: Editorial Bosch, 1990, p 143.
} 
tesitura se mueve la formulación legal del inciso 2 del artículo 75 del Código de Familia. Para obtener un fallo favorable a quien reclama la paternidad apoyado en dicha presunción legal, ha de probarse el carácter notorio de las relaciones maritales con la madre durante el período en que se concibió el hijo. No es suficiente que se prueben tales relaciones notorias, antes o después del momento en que se presume la concepción, sino que se pruebe la conexidad entre las relaciones sexuales de la pareja y la fecha de la concepción. Para inducir el hecho presumido, tiene aquí la parte actora del proceso que pechar con la carga de la prueba del hecho base, esto es, el probar ese carácter público de las relaciones maritales, el comportamiento a nivel social, familiar, como pareja, aunque la relación haya sido esporádica. En todo caso, no se pretende reconocer judicialmente la relación como unión matrimonial no formalizada, sino que ello constituya el soporte factual básico para aplicar la presunción legal ${ }^{20}$.

La última de las presunciones a las que alude el mencionado artículo 75, formulada de una manera incompleta, colige la filiación paterna a partir de la posesión de estado. Llama la atención el tratamiento que ofrece nuestro ordenamiento a la posesión de estado al regularla como un supuesto de presunción legal de paternidad. Se trata de una situación de hecho que se manifiesta a través del comportamiento que para con el hijo haya tenido el padre y su familia paterna. Es una idea de apariencia jurídica que se crea frente a terceros, de modo que constituye una situación fáctica que puede conducir a la determinación de la filiación, pero ella por sí no constituye título de legitimación. Por ello, la doctrina exige en aras de su admisión tres factores el nomen, el tractatus y la fama. De ellos el Código de Familia solo hace una pálida alusión al tractatus, cuando refiere que la condición de hijo se haga ostensible por actos propios del padre o de su familia, pero nada alude a la llevanza del apellido paterno, ni tampoco al reconocimiento social de la condición de hijo que pueda tener las personas que viven en el entorno en que el hijo se desenvuelve. La parquedad de la norma familiar da al traste con la clásica concepción que de la posesión de estado del hijo concibe la doctrina científica.

\subsection{LAS PRESUNCIONES FILIATORIAS DE MATERNIDAD EXTRAMATRIMONIAL}

En relación con las presunciones de maternidad, estas quedan reducidas a dos, por expresa remisión hecha por el artículo 76 al artículo 75 del Código de Familia, a saber: La existencia de documento indubitado en que pueda inferirse la declaración de maternidad y

\footnotetext{
20 En Sentencia No. 743 de 27 de diciembre del 2007, del Tribunal Municipal de Arroyo Naranjo, en Ciudad de La Habana (ponente Enríquez Sordo), el tribunal se apoya en tal presunción, entre otras, para acceder a la demanda, en proceso ordinario, sobre reclamación de paternidad y a tal fin expresa: "... del análisis de las actuaciones y de las pruebas practicadas, de conjunto y por separadas y acorde con los principios de la lógica y las normas determinantes de su eficacia, se pudo constatar que el señor (...) y la señora (...) mantuvieron una relación estable, comportándose como marido y mujer durante el período en que tuvo lugar la concepción, y que según reconoce la demandante en su escrito de contestación, dicha situación se prolongó hasta aproximadamente tres meses después de haber quedado embarazada (...), momento en el que la pareja rompió sus relaciones (...)”.
} 
la posesión de estado. Es lógico, no obstante, que el legislador refuerce las presunciones de paternidad sobre las de maternidad, pues sobre la primera siempre existirá más incerteza respecto de la segunda, en tanto que la maternidad quedará probada por el hecho del parto y la identidad del hijo.

\subsection{PRESUNCIONES FILIATORIAS, MATRIMONIO Y UNIONES MATRIMONIALES PUTATIVAS}

Las presunciones filiatorias estudiadas tienen plena eficacia en supuestos de matrimonio o uniones matrimoniales putativas. El hecho de que un matrimonio sea declarado nulo por la existencia de un impedimento de ligamen en uno de los cónyuges o que la unión de hecho no pueda ser reconocida judicialmente porque uno de los miembros de la pareja carece de aptitud legal por esa misma razón, no impide que en tales supuestos (matrimonios putativos o uniones de hecho putativas), además de los efectos que el Derecho concede al cónyuge o al miembro inocente que ha actuado de buena fe, se hagan extensivo en todo momento a los hijos. Y ese es el sentido del artículo 18, segundo párrafo del Código de Familia, que aun con deficiente redacción ofrece tal protección. De esta manera los hijos habidos de un matrimonio putativo estarían amparados por las presunciones filiatorias contenidas en el artículo 74 del Código de Familia en los supuestos fácticos contenidos en las presunciones.

En relación con los hijos habidos de una unión estable, pero carente de singularidad y de aptitud legal con respecto de uno de los miembros de la pareja, para que operen tales presunciones (me refiero una vez más a las contenidas en el artículo 74 del Código de Familia), requerirán que su progenitora haya interesado judicialmente el reconocimiento de los efectos de la unión putativa por haber actuado de buena $\mathrm{fe}^{21}$, y que tal reclamación haya tenido éxito. Como expresa la profesora Mesa Castillo: “(...) al igual que en las uniones reconocidas judicialmente singulares y estables (...) debe surgir si se reconoce la buena fe en uno o ambos convivientes, la presunción de que los hijos habidos son de ambos, pues aunque se trate de una unión anulada por el impedimento de ligamen, y tampoco se trata de un matrimonio pu-

\footnotetext{
21 Igual que en el matrimonio putativo, la buena fe resulta requisito indispensable para que se reconozca la unión de hecho putativa, solo que en esta el momento de su apreciación va a ser distinto, pues deberá ser constante, a diferencia de lo que ocurre en el matrimonio putativo donde ha de exigirse tan solo al momento de la formalización del acto matrimonial. En la unión de hecho putativa, la buena fe ha de entenderse como el desconocimiento o ignorancia acerca de la existencia de un ligamen por parte del otro miembro de la pareja. Ha de ser apreciada en todo momento y debe ser demostrada día a día mediante la convivencia y el deseo de mantener una vida común, pues no existe la formalización de acto alguno. En este sentido ha dicho la Sala de lo Civil y de lo Administrativo del Tribunal Supremo en su Sentencia No. 142 de 20 de marzo de 2007, primer Considerando (ponente BOLAÑOS GASSÓ) que: “... la esencia de las reclamaciones del supuesto de la buena fe a que se contrae el segundo párrafo del artículo dieciocho del Código de Familia (...) está referida a la carencia de aptitud legal para la legalización de unión de esa naturaleza, lo que no se identifica con el de la falta de singularidad, habida cuenta que el efecto de la acción en primer orden mencionada responde al supuesto del desconocimiento por parte de quien interesa su reconocimiento, de que la persona con quien ha mantenido relaciones maritales estuviera unido en matrimonio formalizado con una tercera (...)".
} 
tativo, tiene los beneficios protectores de la buena fe (...)"22. De ser así, la sentencia judicial que reconoce la buena fe y, en consecuencia, los efectos que ella lleva consigo, haría las veces de la certificación de matrimonio expedida conforme con el asiento de inscripción del matrimonio, para probar el hecho base del que puede colegirse el hecho inducido (la filiación). Seamos más explícitos, probada que existió una unión putativa entre el señor $\mathrm{A}$ y la señora $\mathrm{B}$, si el nacimiento del hijo C, operare después de tener éxito la demanda de reconocimiento de los efectos de la buena fe, como se trata de una unión putativa, en la cual el Tribunal deberá declarar la fecha de inicio y de terminación de la unión, si bien esta no será reconocida como unión matrimonial no formalizada por estar carente de los requisitos de singularidad y de aptitud legal en relación con uno de los miembros de la pareja y no abrirá un folio registral en el libro de matrimonios del Registro del Estado Civil, se entenderá a los efectos legales que el hijo ha nacido durante la vida marital putativa de la pareja, razón por la cual le ampararía la presunción filiatoria contenida en el inciso 1 del mencionado artículo 74. Mientras, si el hijo nace dentro de los 300 días de extinguida la unión putativa, fecha que deberá aparecer contenida en la mencionada sentencia, podrá presumirse que es hijo de la persona con la cual la madre mantenía esa unión, amparado ahora en el inciso 2 del artículo 74.

En todo caso, parto de la hipótesis de que quien no cumple con la singularidad, motivo por el cual no es reconocida la unión matrimonial no formalizada es el hombre, pues si fuere la mujer, la situación se tornaría hartamente compleja, ya que si su pareja en la unión de hecho demuestra su desconocimiento sobre la existencia del matrimonio que ella mantenía y promueve con éxito el reconocimiento de su buena fe en esa unión matrimonial putativa, al amparo del mencionado artículo 18, segundo párrafo del Código de Familia, entonces nada evitaría la turbatio sanguinis, pues las presunciones filiatorias contenidas en el artículo 74 operarían para ambos, de modo que solo cabría demostrar la verdadera paternidad en un proceso filiatorio, tras las prácticas de las pruebas genéticas pertinentes, sobre todo la de $\mathrm{ADN}$, a los fines de determinar científicamente la filiación. De todas formas, recordemos que las presunciones filiatorias tienen naturaleza relativa y, en consecuencia, pueden destruirse con prueba en contrario.

Quiero dejar esclarecido que, en todo caso, la protección de los hijos está garantizada con independencia de que estos sean habidos en matrimonios putativos o uniones factuales o de hecho putativas, solo que siendo hijos de personas que han desarrollado una vida marital, si bien putativa, estarían amparados en las presunciones del artículo 74 del Código de Familia que están concebidas para los hijos nacidos en matrimonios formalizados o reconocidos judicialmente. Siempre quedarían a salvo, a los efectos de determinar su filiación, la cobertura que brindan las presunciones de paternidad y de maternidad contenidas en los artículos 75 y 76 del Código de Familia para los hijos habidos extramatrimonialmente y las acciones

22 Mesa CASTillo, Olga. En: Derecho de Familia, Módulo 2 - El matrimonio, VI Parte - Nulidad del matrimonio. La Habana, Cuba: Félix Varela, 2005, pp. 85-86. 
filiatorias o de estado con todas las garantías necesarias para investigar la filiación paterna o materna del hijo.

\section{EL RECONOCIMIENTO DE FILIACIÓN}

Uno de los modos de determinación de la filiación es el reconocimiento de esta, que consiste en un acto jurídico familiar a través del cual se establece la paternidad y la maternidad de los hijos nacidos fuera del matrimonio. Su principal efecto es constituir el estado de filiación a cuyo tenor los hijos pueden ejercitar como tales sus derechos, estado filiatorio que, como ha apuntado la Sala de lo Civil y de lo Administrativo del Tribunal Supremo en el único Considerando de su Sentencia No. 153 de 29 de mayo de 2009 (ponente Carrasco Casi), "no es más que la situación o posición que una persona ocupa dentro de la familia en calidad de hijo constatado en el Registro del Estado Civil del pais". El reconocimiento de filiación no siempre coincide con la verdad biológica, por cuanto, el recognoscente podría estar consciente de que el hijo que reconoce como suyo no ha sido procreado por él.

Se discute doctrinariamente si con el reconocimiento estamos en presencia de un acto o de un negocio jurídico, pero la previsión de los efectos jurídicos del reconocimiento dispuesta ex lege, apunta hacia el primero, sus efectos no pueden ser derogados por la voluntad del recognoscente.

La regulación jurídica del reconocimiento es expresión palpable del tratamiento que el Derecho cubano le da a la filiación en su conjunto. Como acto jurídico que es, según el artículo 8 y la Disposición Final Primera del Código Civil, le resultan de aplicación los artículos 49 y siguientes del Código Civil, en lo que resulte atinente, pues no se olvida que estamos en presencia de un acto jurídico familiar, pero es necesario colmar el vacío legislativo, determinando el estatuto legal a que responde dicho acto jurídico.

\subsection{NATURALEZA DEL ACTO DE RECONOCIMIENTO}

Se trata de un acto jurídico individual, que compete al padre y a la madre, solo surte efectos en relación con el padre o la madre que ha reconocido, pero no se comunican los efectos; unilateral, en tanto contiene una sola declaración de voluntad, la del sujeto recognoscente; puro, no es dable supeditarle ningún elemento accidental, como la condición, el término y el modo, se reconoce a la prole sin más; irrevocable, en tanto que no le cabe al recognoscente volver sobre sus actos, en razón de la expectativa jurídica creada por el acto mismo del reconocimiento a favor del hijo reconocido, la protección del interés superior del menor cuando el reconocido así lo fuere, también acude a favor de este elemento de su naturaleza jurídica; personalísimo, pues solo cabe del padre o madre, sin que sea posible el otorga- 
miento de un negocio de apoderamiento, ni aun cuando este es especial ${ }^{23}$; expreso, en tanto el recognoscente debe dejar bien esclarecida su intención con ese acto de asumir la paternidad o la maternidad; con efectos retroactivos, pues una vez reconocida la paternidad o la maternidad del hijo, se entiende que se es padre o madre desde el nacimiento del hijo y no desde el acto mismo del reconocimiento.

\subsection{El SUJETO RECOGNOSCENTE}

Ahora bien, quién está legitimado para interesar el reconocimiento. En principio, el otro progenitor que no lo ha reconocido y en todo caso el hijo, ya sea menor de edad o mayor de edad. El Derecho familiar cubano impone, eso sí, el "consentimiento" del progenitor que ya le reconoció, para que el otro pueda reconocerlo, sin su anuencia, no cabe en vía registral el reconocimiento y tendría entonces que reclamar la filiación por vía judicial, aún con oposición del otro progenitor.

Si se tratare de una persona mayor de edad, será necesario también su "consentimiento”. En relación con los menores de edad, lamentablemente, la ausencia de regulación de una capacidad progresiva, impide que los menores, mayores de cierta edad, expresen claramente su anuencia a que el presunto padre les reconozca. Es un absurdo que en la actualidad no se escuche al menor en asunto de esta índole y que en vía registral se admita un reconocimiento de un menor de edad, con la sola participación del otro progenitor que le había reconocido. Una vez más nuestro Derecho familiar no está a tono con los tiempos que corren, ni con la Convención Internacional sobre los derechos del Niño que en su artículo 12.1 deja establecido que: "Los Estados Partes garantizarán al niño que esté en condiciones de formarse un juicio propio el derecho de expresar su opinión libremente en todos los asuntos que afectan al niño, teniéndose debidamente en cuenta las opiniones del niño, en función de la edad y madurez del niño". Y en qué otro asunto pudiera tener más interés un niño que en el reconocimiento que su presunto padre quisiera hacer sobre la paternidad sobre él. En todo caso, los intereses del menor han de quedar a salvo con la intervención del fiscal, el cual debiera estar presente aun en la hipótesis en que en sede registral se pretenda reconocer la filiación, si bien la Ley del Registro del Estado Civil no lo prevé, a diferencia del supuesto de reconocimiento en sede judicial (vid. artículo 81, segundo y tercer párrafos del Código de Familia).

23 En este sentido vale la pena acotar de que aun cuando hay ordenamientos jurídicos en los cuales es posible el otorgamiento de escritura pública de poder especial para que el apoderado reconozca la paternidad o maternidad de su poderdante, el solo otorgamiento del poder lleva implícito tal reconocimiento, además de que resulta absurdo concurrir ante notario para otorgar escritura de apoderamiento a tal fin, cuando resulta mucho más expedito que otorgue directamente escritura pública de reconocimiento de filiación, la cual per se constituirá fuente del asiento de inscripción del nacimiento del hijo, siempre que, por supuesto, se cumplan con los otros requerimientos que la ley exige, tratándose el reconocido de un hijo menor de edad, o de un hijo mayor de edad. 


\subsection{CAPACIDAD PARA EL RECONOCIMIENTO}

No menos interesante se ofrece el tema de la capacidad para el acto de reconocimiento de filiación que otorga aristas sumamente atractivas en el orden doctrinario. El Código Civil cubano es muy parco en relación con el ejercicio de la capacidad jurídica. Al tenor del artículo 29, tienen pleno ejercicio de la capacidad jurídica los mayores de 18 años y los menores que hayan formalizado matrimonio. Como arguye la profesora Valdés Díaz: "La capacidad de ejercicio presupone que la voluntad e inteligencia del individuo han alcanzado un grado de madurez indispensable para conducirse libre y racionalmente en la vida social" 24 . Empero, hay actos en que, por su propia naturaleza, debiera habilitarse el ejercicio de la capacidad a menores que no han arribado a la mayoría de edad. Me refiero expresamente al reconocimiento de filiación, cuando el progenitor no ha alcanzado la mayoría de edad, lo que en el contexto jurídico cubano se convierte en un verdadero dédalo jurídico, al tener que concurrir los padres del menor, a mi juicio, a completar el ejercicio de la capacidad, más que a representarlos en dicho acto, pues con ello se rompería con el carácter personalísimo del acto. Es el padre quien debe reconocer la prole y no el abuelo en representación del padre, también menor de edad. Verdaderamente es un contrasentido autorizar el matrimonio a las mujeres de 14 años y a los hombres de 16 años, e impedir que los que no se hayan casado no puedan reconocer per se la prole. Es cierto que la geometría jurídica daría la razón, el menor que contrae matrimonio, con la autorización procedente, que adquiera al amparo del artículo 29.1 b) del Código Civil, la plena capacidad jurídica, por ello le es dable realizar válidamente cualquier acto jurídico, salvo aquellos para los que la ley impone una edad especial, pero el Derecho no puede ir al margen de la realidad social, y en un país como Cuba en que por su idiosincrasia y sus costumbres tropicales no es nada excepcional que nazca un niño de padres menores de edad (lamentablemente todavía acontece), el Derecho debiera potenciar la regulación de una capacidad progresiva que habilite $v$. gr., a quien ha procreado un hijo a reconocerle, por supuesto en los márgenes de permisibilidad. Es aconsejable que se asimilara a la edad excepcional para constituir matrimonio según el artículo 3 del Código de Familia. Por fortuna, el artículo 87 del Anteproyecto de Código de Familia se hace eco de esta situación y en una posición muy permisiva, habilita a los menores de edad a reconocer al hijo procreado, con independencia de la edad que tengan, así sea esta incluso inferior a la que el legislador establece para que pudiera constituir un matrimonio, aunque esto sea excepcional. Según el Anteproyecto es suficiente tener "la capacidad natural para haberlo engendrado". De convertirse en lege lata, se pondría fin a este dilema doctrinal, con innegables consecuencias prácticas, que hoy día motiva la concurrencia de los progenitores al acto de reconocimiento, como dije,

24 Valdés Díaz, Caridad del C. "Comentarios al artículo 29". En: Comentarios al Código Civil cubano, Tomo I, Libro I, disposiciones preliminares. Relación jurídica, director Leonardo B. Pérez Gallardo. La Habana, Cuba: Félix Varela, 2000. 
con plena ruptura del carácter personalísimo de dicho acto, en lo cual cabe insistir que, a tenor del artículo 85.4 del Código de Familia, se trataría de un supuesto de complemento de ejercicio de la capacidad, y no de representación de los menores en el acto mismo del reconocimiento de la prole, como lo entienden los operadores del Derecho en Cuba ${ }^{25}$. No obstante, habría que indagar en el alcance del precepto que se propone en el Anteproyecto de Código de Familia, a fin de entender si con el reconocimiento de la filiación por sus padres, menores de edad, estos pueden ejercitar plenamente la representación de sus hijos, en razón de la patria potestad que ostentarían sobre estos, pues si ellos necesitan representación paterna y materna para realizar los actos jurídicos en los cuales intervienen per se (vid. artículo 85.4 del Código de Familia), pudiera pensarse, en opinión que no comparto, de iure condendo, que esa representación será necesaria para realizar los actos jurídicos de sus hijos, de modo que tan solo sería el reconocimiento de la prole, lo que viabilizaría el futuro Código de Familia, pues hasta tanto no se reformulen las normas del Código Civil sobre el ejercicio de la capacidad jurídica, los menores de edad, con hijos o sin hijos, estarían en igualdad de circunstancias. A mi juicio, tratándose de personas menores de edad, no casadas, que han tenido hijos, debiera reconocérsele pleno ejercicio para realizar ciertos actos jurídicos, más allá de los incluidos en el artículo 30 a) del vigente Código Civil en ocasión de regular la capacidad restringida, en tanto, que para otros actos con más trascendencia patrimonial, la actuación de los padres de los primeros debiera limitarse a complementar su capacidad jurídica, y no a suplir el ejercicio de dicha capacidad, motivo por el cual, no debiéramos hablar de representación de los padres, y sí de mero complemento del ejercicio de la capacidad jurídica.

Tema distinto opera respecto de las personas declaradas judicialmente incapacitadas y de aquellas otras que aun sin dicha declaración son personas dementes, insanas psíquicamente, las cuales pueden sin ningún obstáculo engendrar, en tanto ello es un hecho o dato biológico, pero no podrán reconocer, si no es con la autorización de su tutor, o de quien lo fuere, cuando no exista una previa declaración judicial de incapacitación, oída el parecer del fiscal, y con aprobación judicial. No se olvide que circunstancias de esta naturaleza pueden acaecer, pues si bien a las personas incapacitadas se les veda por el Derecho para realizar per se actos jurídicos, sancionados en todo caso con la nulidad absoluta, físicamente suelen estar aptas para la procreación y una vez nacido el hijo, habría que encarar desde el Derecho los efectos filiatorios de esta situación, en el que uno de sus protagonistas carece de ejercicio de la capacidad jurídica ${ }^{26}$. Otra omisión del legislador cubano, en la que, al parecer, también incurre el autor del actual Anteproyecto de Código de Familia.

25 Sobre el tema son interesantes las valoraciones que hace OJEDA RODRÍGUEZ, Nancy de la C. El reconocimiento de hijos y la función notarial. La Habana, Cuba: Conferencia dictada en la VII Jornada Internacional del Notariado cubano, del 29 al 31 de mayo del 2008.

26 Téngase en cuenta además, que no se trata de un caso simple, sin más supuestos. Así, v. gr., por citar algunos, cabría que la situación que motivó la incapacitación del sujeto, le sobreviniera, de modo que en el momento en que operó la concepción estaba con plena lucidez mental. 


\subsection{EL SUJETO RECONOCIDO. ESPECIAL REFERENCIA AL RECONOCIMIENTO FILIATORIO RESPECTO DEL NASCITURUS}

Tampoco ofrece el ordenamiento jurídico cubano sistematicidad alguna sobre el sujeto pasivo del reconocimiento. ¿Quiénes pueden ser reconocidos? Como ya he apuntado, el reconocimiento puede recaer sobre un menor de edad o sobre un mayor de edad, pero antes de analizar con detenimiento tales supuestos, resulta preciso expresar que este puede extenderse al nasciturus. En efecto, el artículo 25 del Código Civil cubano regula la protección jurídica del nasciturus, supeditada a la conditio iuris del nacimiento, lo cual, a mi juicio, no quiere decir, que durante dicho estadio, cuando aún es un ser humano in fieri le esté impedido al padre reconocer por escritura pública notarial o por testamento, su paternidad. Precisamente si al concebido se le tiene por nacido para todos los efectos que le sean favorables, ese reconocimiento filiatorio, cuya eficacia se supedita al nacimiento con vida del nasciturus, es uno de los efectos a los que alude el precepto. Por supuesto, el efecto del reconocimiento se supeditará al cumplimiento de la mencionada conditio iuris impuesta por el legislador. Aun cuando al momento del nacimiento del hijo, el padre ya haya fallecido, la filiación se habrá determinado a través del reconocimiento voluntario del padre, instrumentado ante notario. El Anteproyecto del Código de Familia lo prevé en el artículo 85.4 como un supuesto de reconocimiento voluntario de la prole ${ }^{27}$.

Ahora bien, si con posterioridad al reconocimiento, el presunto padre formalizara matrimonio con la madre del menor, antes del parto, aun cuando no se le reconozcan efectos retroactivos al matrimonio, entonces la filiación del hijo también estaría protegida por la presunción filiatoria reconocida en el artículo 74.1 del Código de Familia, empero, tratándose del reconocimiento voluntario de filiación de un modo de determinación de esta, dirigido con exclusividad a la asunción de paternidad o de maternidad, tendría a mi juicio, más fuerza dicho reconocimiento respecto de la filiación del concebido que la propia presunción, que por el carácter relativo, pudiera destruirse con prueba en contrario, en tanto, el reconocimiento por naturaleza es irrevocable, amén de la posibilidad de interesar su nulidad en razón de la existencia de los vicios en la manifestación de voluntad (vid. artículos del 69 al 75 del Código Civil). No obstante, como el asiento de inscripción del nacimiento se practica por el registrador del estado civil, tras el nacimiento del hijo, al estar casados los padres al momento del nacimiento, con independencia de aquel en que obró la concepción, dicho oficial actuará conforme con lo establecido en el artículo 45 de la Ley del Registro del Estado Civil pues la declaración de la madre al momento de dicha inscripción surtirá efectos filiatorios para el padre por razón de la presunción de paternidad contenida en el artículo 74.1 del Código de Familia, sin que fuera necesario aportar copia de la escritura pública de reconocimiento de filiación.

27 En la doctrina cubana abrazan esta tesis OJEDA RodRíGUEZ, Nancy de la C. op. cit. (n. 25), pp. 46-47. 
$\mathrm{Si}$, por el contrario, acontece lo más común que es que quien reconoció su posteridad, no formalice matrimonio con la progenitora del hijo, será de aplicación entonces lo previsto en el artículo 47 de la Ley del Registro del Estado Civil, de modo que cabría la posibilidad de que concurrieran ambos, o $v$. $g r$., solo la madre con la copia de la escritura de reconocimiento de filiación, lo que haría prueba plena respecto del padre, a pesar de que este haya ya fallecido. A mi juicio, en este supuesto, aunque la ley exige presencia física, dicha presencia debe ser sustituida por la copia de la escritura de reconocimiento de filiación, pues no se exige que en el acto de reconocimiento se ratifique una voluntad anteriormente exteriorizada bajo la fe pública de un notario. El reconocimiento habrá surtido plenos efectos legales, una vez cumplida la conditio iuris impuesta por el legislador en el artículo 25 del Código Civil. La situación más comprometedora, operaría si la madre se niega a aportar la escritura pública de reconocimiento de filiación otorgada por el padre, cuando el hijo, era tan solo un nasciturus, pues en tales circunstancias, se actuaría conforme lo previsto en el artículo 52 de la Ley del Registro del Estado Civil, en relación con el artículo 51 del mismo cuerpo legal, pues hecha la declaración de voluntad por la madre sin mencionar el nombre del padre, este para reconocer la filiación requerirá del "consentimiento" de la madre como requisito sine qua non para que su reconocimiento tenga lugar y, en consecuencia, se adicione en el asiento de inscripción por el registrador del estado civil, la filiación paterna del hijo. De lo contrario, tendría que ejercitar la acción de reclamación de paternidad. Por ese motivo sería aconsejable, si las circunstancias lo permiten, que quien reconozca la paternidad del nasciturus, haga constar la aquiescencia de la madre al respecto, a menos que tras el nacimiento del hijo ambos progenitores declaren su paternidad y maternidad respectivamente ante el oficial del Registro del Estado Civil correspondiente, pero en este caso sería un contrasentido el haber otorgado escritura pública de reconocimiento de filiación sobre el nasciturus. Para ser más práctico, este reconocimiento, por regla general, será dado por el presunto padre, a instancia de la madre, como una garantía que tendría esta para que su futuro hijo pueda constar no solo con filiación materna, sino también con filiación paterna, sin embargo, los supuestos que narro, no deben dejar de ser atendidos tanto por la doctrina, y sobre todo por el legislador.

\subsection{RECONOCIMIENTO DEL HIJO FALLECIDO}

En relación con las personas fallecidas, también resulta omisa nuestra legislación ¿En qué caso no pueden reconocerse las personas que al momento del reconocimiento ya han fallecido, o sea, el hijo premuerto? La doctrina científica ${ }^{28}$ ha sido cautelosa en este tema y es partidaria de que el reconocimiento proceda siempre que el reconocido haya dejado descen-

28 Rivero Hernández, Francisco, op. cit. (n. 4), p. 121 y Parra BeníteZ, Jorge. La filiación en Derecho de Familia. Bogotá, Colombia: Leyer, 2008, pp. 167-168. 
dencia pues aquí se justificaría el interés atendible para la posteridad del pretenso reconocido $^{29}$, que además de tener la filiación paterna o materna de la cual carece, pudiera sucederle por causa de muerte al abuelo. Por este motivo, se suele limitar el reconocimiento de un hijo fallecido a los casos en que este haya dejado descendencia, la cual, de ser mayor de edad, a mi juicio, tendría que "consentir", de la misma manera que habría tenido que "consentir" el presunto hijo fallecido, en tanto si son menores de edad, sus intereses serían protegidos por el representante legal que tuvieren, el padre o la madre, o el tutor, quienes deben prestar el "consentimiento", con intervención fiscal. Tratándose de varios descendientes, si se pretende que el reconocimiento se haga en sede registral, aún el vacío normativo existente, habría que acreditar por acta notarial de notoriedad los descendientes del fallecido, que no tienen por qué coincidir con los herederos, pero tratándose de un acto que atañe al estado civil de aquellos, y no al de los herederos, serían los primeros los que deberían estar legitimados para "consentir" el reconocimiento, en caso de que no exista unanimidad, la acción tendría que ejercitarse en sede judicial.

\subsection{INTERVENCIÓN FISCAL Y “CONSENTIMIENTO” DEL OTRO PROGENITOR QUE YA HA RECONO- CIDO LA PROLE EN EL RECONOCIMIENTO FILIATORIO}

En el acto mismo del reconocimiento del hijo, nada prevé nuestro Código de Familia ni la Ley del Registro del Estado Civil ni su Reglamento, sobre la intervención fiscal, lo cual resultaría aconsejable como una garantía más para los intereses del menor. Si el progenitor recognoscente tiene el beneplácito del otro progenitor que previamente había reconocido al hijo o de su representante legal, en ausencia de aquel, en el entendido de que se trata del "consentimiento" como lo denomina la ley, entonces según establecen las normas procedimentales administrativas contenidas en la nombrada Ley del Registro del Estado Civil (vid. artículo 51) se procederá a tener por eficaz el reconocimiento paterno o materno y a completar el asiento de inscripción del nacimiento del hijo con los datos concernientes a la filiación que faltaba. Reconocimiento que registralmente obrará en nota al margen del asiento de inscripción de nacimiento del hijo (vid. artículo 42 j)). Caso contrario, procedería ejercitar la acción correspondiente por la vía judicial que no tiene un verdadero amparo legal en nuestro ordenamiento. De tratarse de un hijo mayor de edad, aunque el artículo 52 no lo deja claramente establecido, será suficiente el "consentimiento" de este. Sin él, no sería procedente el reconocimiento. El fundamento que encuentra la doctrina para esto, es que de la misma manera en que no es

\footnotetext{
29 En tanto, si no deja descendientes el reconocimiento póstumo del hijo, quizás solo sería el remedio para expiar la culpa de quien, movido por la duda o la incertidumbre o quién sabe por qué otros motivos, no lo reconoció en vida. En ausencia de hijos, serían precisamente los padres quienes le heredarían (vid. artículo 515 del Código Civil) y resultaría entonces contraproducente que el padre que no reconoció al hijo durante la vida de este, se convierta en heredero por dicho reconocimiento filiatorio.
} 
posible impedirle al padre reconocer, tampoco resultaría justo imponerle el reconocimiento al hijo, cuando se trata de un reconocimiento tardío, pasadas las etapas en las que son más necesarias la presencia de los padres, como la infancia y la juventud. Resulta verdaderamente contraproducente que no se tome en cuenta el criterio de un hijo mayor de edad que ya tiene formada su propia familia, para que sobre él recaiga ahora un reconocimiento paterno o materno en una época en la que moralmente tendría toda la autoridad para rechazarlo ${ }^{30}$.

\subsection{MOdOS DE EXPRESAR EL RECONOCIMIENTO. DISTINCIÓN DE LA INSCRIPCIÓN}

Cabe también acotar que nuestro Derecho vigente solo prevé como modos de expresar el reconocimiento de filiación, la declaración ante el funcionario del Registro del Estado Civil (vid. artículos 40, 41, 52 de la Ley del Registro del Estado Civil y artículos 84, 85 y 86 de su Reglamento) y ante notario público por escritura pública. Más controvertido es el acto testamentario, en relación con el cual hay un mutismo generalizado en todo el ordenamiento jurídico. Las normas reguladoras del testamento en el Código Civil no mencionan en lo absoluto la posibilidad de un reconocimiento filiatorio como contenido del testamento, lo cual no priva de que ello pudiera acontecer, pues el contenido de tal acto no puede quedar reducido al dispositivo patrimonial del testador. Al ser el testamento el reservorio de las más disímiles manifestaciones de voluntad, nada priva que en él pueda estar contenidas declaraciones de voluntad que no sean típicamente testamentarias como el reconocimiento de un hijo que, en nuestro caso, ni tan siquiera se prevé en normas jurídicas distintas al Código de Familia. Criterio disímil parece introducir el Anteproyecto de Código de Familia que incorpora en el artículo 86 el reconocimiento testamentario, con efectos distintos de los que pudiera tener hoy, ya que un reconocimiento por testamento en Cuba no devendría en un título legítimo de filiación, sino en un medio de prueba a aportar en el proceso, con la eficacia que la ley le concede, eso sí, a los documentos públicos notariales, si el testamento fuere notarial (vid. artículo 294 de la LPCALE). Tales efectos que predica el Anteproyecto, sería un viraje importante en la manera en que se ha venido concibiendo el reconocimiento filiatorio ex testamento. Este tendría el mismo valor que la declaración ante el oficial del Registro del Estado Civil, o sea, sería un modo de expresar el reconocimiento de filiación directamente inscribible en el asiento de nacimiento del hijo, siempre que se "consienta" por el hijo mayor de edad o por el representante legal de los menores de edad, dígase el tutor o el otro progenitor, que al tener este último dicha representación es porque ha sido quien ya lo ha reconocido, pero además previa audiencia fiscal, lo que me parece loable en el Anteproyecto al ofrecer una garantía más, de indubitable valor, en tanto debe el fiscal velar porque el reconocimiento testamentario contenga la verdad material del dato biológico de la procreación y no un subterfugio en fraude de ley.

30 GUZMÁN Ávalos, Aníbal, op. cit. (n. 11), p. 128. 
Por último, cabe acotar que el reconocimiento del hijo por el padre o la madre, acto jurídico en el que el uno o el otro admite su condición de progenitor y con ello asume los efectos que la ley prevé en materia filiatoria, creando en sí la relación jurídica filiatoria, es disímil a la inscripción, acto de naturaleza administrativa que practica el funcionario y oficial a cargo del Registro del Estado Civil, a cuyo tenor se abre un folio registral, haciéndose coincidir con el asiento de inscripción del nacimiento, cuya fuente lo ha sido la declaración conjunta de los padres o el reconocimiento individual de cada uno de ellos (vid. artículo 40 a) de la Ley del Registro del Estado Civil), o la sentencia ejecutoriada de tribunal competente (vid. artículo 40 e) de la mencionada ley).

\section{LAS ACCIONES FILIATORIAS}

Las acciones filiatorias son las acciones de estado por excelencia. Su finalidad es la declaración o la privación de una filiación controvertida.

\subsection{LA ACCIONES DE RECLAMACIÓN DE FILIACIÓN}

Estas acciones tienen por objeto la determinación de una filiación hasta el momento no determinada formalmente.

Tienen su sede en el Código de Familia en los artículos 77 y 81 . El artículo 77 regula la acción de reclamación de filiación en sentido estricto, para la cual están legitimados tanto el hijo como la madre o el padre que lo haya reconocido frente a quien no lo haya hecho. Es dable aclarar que la norma tiene una formulación ampulosa, pues de su lectura cabría colegir la necesidad de que la acción sea ejercitada, por el hijo y por el padre o la madre que le haya reconocido, si así fuere, se exigiría un litisconsorcio activo necesario para sostener la acción de reclamación de la filiación, o sea, que esta sea interpuesta por ambos. Una segunda lectura, con un sentido más laxo, permitiría entender que entre los legitimados para el ejercicio de la acción están tanto el uno como el otro. Eso sí, de lo que no cabe duda es que la sistemática del Código de Familia no es nada loable. La acción de reclamación nada tiene que ver con las presunciones filiatorias, motivo por el cual, no es dable que sea ubicada en la Sección Segunda del Capítulo I, del Título II de dicho Código, dedicada precisamente a tales presunciones.

La acción de reclamación como acción de estado es imprescriptible, sin embargo, en el artículo 77 nada dispone el legislador cubano. Si se tratare de un hijo menor de edad quien ejercita la acción, deberá concurrir representado por el fiscal, pues si la madre también la ejercita per se, no podría ejercitarla en representación del menor (vid. artículo 60 y 63 del Código Civil). Si se trata de una persona mayor de edad, aunque las normas no lo reconozcan expresamente, tendrá que ejercitar la acción el hijo, y en todo caso, conjuntamente con la madre o el 
padre, pero nunca el progenitor recognoscente sin la anuencia del hijo cuya filiación se reclama.

Reconoce también el Código de Familia en su artículo 81, la acción de reclamación de naturaleza mixta, pues se trata de una acción que lleva implícita la previa impugnación de la filiación ya determinada por el reconocimiento de un tercero. Se trata de una acción dirigida a impugnar una filiación preexistente. Tanto la acción de reclamación en sentido estricto como la acción de reclamación e impugnación de la filiación tienen por cometido investigar la paternidad o la maternidad, según contra quién se ejercite. Al tratarse de acciones de estado tienen por cometido fijar, determinar o rectificar el status filii del hijo.

De igual manera tiene esta naturaleza la acción regulada en el artículo 51 de la Ley del Registro del Estado Civil, precepto que prevé la posibilidad de que el padre que se niegue a aceptar la paternidad en vía registral ${ }^{31}$, pueda en un futuro interesar su reconocimiento, para lo cual será necesario el "consentimiento" de aquel que haya inscrito al hijo o del que lo represente legalmente. De no darse el "consentimiento", entonces franquea la norma la posibilidad de reclamar la paternidad en la manera establecida en la ley, acción para la cual el ordenamiento jurídico cubano no tiene una respuesta legal directa.

Y como apunta el profesor Rodríguez Corría, también se incluye dentro de las acciones de reclamación de filiación, la reconocida en el artículo 52 de la propia ley registral, "similar a la anterior (...), pero que se diferencian en su origen, pues si la anterior el padre había tenido, inicialmente, la posibilidad de reconocer registralmente, en esta caso, nunca la tuvo al no ser citado, por lo que se le ofrece la posibilidad del reconocimiento registral" 32 . Si bien, según el criterio del mencionado profesor, que comparto por su lógica, no debería condicionarse a la aceptación de la madre o padre que ya reconoció, pues éste al no declarar el nombre y la dirección impidió la citación para el reconocimiento voluntario, motivo por el cual, su no "consentimiento", no debiera ser hoy fuente de litigios filiatorios.

\subsection{1. ¿Transmisibilidad mortis causa de estas acciones?}

Tampoco se regula sobre su transmisibilidad mortis causa, tratándose de acciones de estado, fallecido el legitimado para su ejercicio, debiera el legislador determinar si dichas acciones pueden ser ejercitadas por los más propincuos parientes del titular, que no son los herederos voluntarios, pues nada tiene que ver un heredero voluntario, no vinculado parentalmente con el titular de estas acciones, en su ejercicio. Es más, la lógica me indica que si el heredero viera en peligro la sucesión a la que es llamado con el éxito de la acción de reclamación, no la ejercitaría,

31 Rodríguez CORRÍA, Reinerio. La filiación y sus acciones. Algunas reflexiones sobre su regulación y aplicación práctica. p. 12. Se trata de la negación que permite el artículo 48 cuando el padre es citado para aceptar o negar la paternidad. No es ni una oposición, ni una impugnación, sino la posibilidad que le franquea la propia ley de negar la paternidad, sin que ello cause estado, ni le impida en un futuro volver sobre sus actos. No es alegable aquí el principio que prohíbe venire contra factum proprium. 32 Ibid. 
impidiéndole su ejercicio a quien sí tuviere interés legítimo para ello. $v$ gr., el heredero voluntario del padre que intenta el ejercicio de la acción de reclamación de un hijo a quien considera suyo, no ejercitaría la acción, si con ello adquiriera la condición de legitimario el menor hijo y, en consecuencia, pudiera impugnar la institución de heredero testamentaria con la que él se ha visto beneficiado. Tratándose del hijo o hija el fallecido, reconocer la transmisión hereditaria de esta concreta acción resultaría también sumamente polémico, aunque esa es la posición que adopta el artículo 100.3 del Anteproyecto de Código de Familia. Vuelvo a insistir que la transmisión hereditaria no resolverá el problema, lo lógico es que se legitimen post mortem para su ejercicio a los descendientes del hijo, que serían quienes tendrían más interés moral y afectivo porque se investigue la paternidad o la maternidad de su progenitor fallecido, con los efectos que a ellos concierne en su estado civil y no que se transmita iure hereditario ${ }^{33}$. Los herederos no tienen por qué coincidir con los descendientes del hijo y, en consecuencia, el ejercicio de las acciones transmitidas iure hereditario, tienen un sabor puramente patrimonial, pues qué otro interés legítimo tendría un heredero, no pariente del testador, en entablar un proceso filiatorio contra el padre de este para reclamar el status filiatorio de su causante directo, sino que con ello, pudiera resultar beneficiado de alguna sucesión de la cual traería causa el fallecido testador.

\subsubsection{La acción mixta de reclamación-impugnación de fliación}

Prima facie es dable aclarar que lo que se impugna es la filiación no el reconocimiento. Si el hijo ha sido reconocido por un tercero, ello genera un status filiatorio para el hijo que hay que destruir, negar, para una vez obtenido éxito en ello, reclamar la filiación. Se trata de una acción mixta de naturaleza constitutiva, pues va a rectificar o mutar el estatuto filiatorio del hijo. Esta acción viene reconocida en el artículo 81 del Código de Familia. Tampoco se trata de una nulidad parcial del asiento de inscripción del nacimiento, este, en todo caso, se rectificará una vez que la verdad biológica coincida con la verdad jurídica, tras la investigación de la paternidad o de la maternidad a que esta acción conduce.

\subsubsection{Legitimación. Especial referencia a la naturaleza del dictamen fiscal en los proce- sos de esta naturaleza}

Legitimado activamente para ello está el presunto padre o la presunta madre y pasivamente el padre o madre que lo ha reconocido, incluso a sabiendas de que no es suyo, como cuando se reconoce al hijo del cónyuge, y el otro progenitor que consintió el reconocimiento,

\footnotetext{
33 Sobre el tema, ZACCARIA, Alessio. Diritti extrapatrimoniali e successione. Cedam, Padova, 1998, pp. 98-169. Este autor hace un exhaustivo estudio sobre la tutela post mortem de los derechos de la personalidad y, más en general, de algunas categorías de derechos extrapatrimoniales.
} 
tratándose de un menor de edad, según lo dispone el artículo 52 en relación con el artículo 51 de la Ley del Registro del Estado Civil, como requisito sine qua non para que sea eficaz el reconocimiento filiatorio. Por la naturaleza de la acción y las consecuencias que da este conflicto filiatorio, esencialmente de paternidad, puede tener en él un desarrollo intelectual y psicológico del menor, por lo que el Código de Familia en su artículo 81, exige como requisito previo en el trámite judicial que se dé traslado al fiscal para que este dictamine si considera pertinente iniciar el proceso en una etapa en la que el hijo no ha arribado a la mayoría de edad. Compete al fiscal determinar, conforme con las investigaciones que practique, lo que resulte más beneficioso para el interés superior del menor, si indagar hasta la saciedad la verdad biológica de su procreación, en la búsqueda de la verdadera identidad del menor, o suspender esa pesquisa hasta el arribo de la mayoría de edad, pues ello provocaría un mal mayor en el menor teniendo en cuenta además, el entorno familiar en el que se ha desenvuelto, de modo que hay que sopesar ventajas y desventajas en aras de desvelar una verdad que puede herir sentimientos y afectividades en él, al tener que enfrentar una cruda realidad como la de saber que su verdadero padre es una persona distinta a aquel a quien ha profesado cariño, admiración, respeto, y con quien ha entablado un diálogo de franca comunicación y entrega.

Mucho se especula sobre la naturaleza del mencionado dictamen, ¿es un requisito de procedibilidad? ¿Tiene fuerza vinculante? Por mi parte, no lo considero vinculante en modo alguno para el Tribunal. Tiene trascendencia en el orden procesal en tanto, pudiera considerarse un requisito de procedibilidad, de modo que sin él no es posible la continuación de la sustanciación del proceso, lo cual no quiere decir que en el orden sustantivo vincule al Tribunal hasta tal punto que un dictamen negativo del fiscal, lleve al Tribunal a actuar inexorablemente de la manera que establece el tercer párrafo del artículo 81 del Código de Familia ${ }^{34}$. Este, al parecer, es el criterio de la Sala de lo Civil y de lo Administrativo del Tribunal Supremo que en su Sentencia No. 222 de 31 de julio de 2009, único Considerando (ponente Acosta Ricart), deja palmariamente establecido que "este dictamen no resulta en modo alguno vinculante al derecho sustantivo, pues es solo de orden procesal”.

34 En sentencia que resuelve el recurso de casación interpuesto por el fiscal acusando una inadecuada valoración del tribunal de instancia del dictamen evacuado por la fiscalía al amparo del artículo 81, segundo párrafo del Código de Familia, el Alto Foro revoca la sentencia dictada por el tribunal a quo, para lo cual se apoya en “... que reconocido por las alegaciones del propio demandante que mantuvo relaciones amorosas con la madre de la menor cuya paternidad interesa, las que culminaron ante la duda que en él provocó el embarazo de la misma en relación con el que la reconoció como suya, con el que sostuvo relaciones la progenitora con anterioridad al accionante, quien a partir de su nacimiento le ha prodigado afecto paternal y se ha encargado de cumplir las obligaciones que dicho lazo consanguíneo implica, resulta contrario a los intereses de la menor sustanciar un proceso para cuestionar dicha paternidad, tal y como el Fiscal dictaminó al cumplimentarse lo establecido en el artículo 81 del Código de Familia, máxime si el promoverte no enuncia razones que así lo ameriten, pues de sus alegaciones se infiere que hubo inmediatez entre ambas relaciones maritales, así como invoca el parecido físico con la menor lo que no son motivos de naturaleza tal que motiven un proceso como este, a contrario sensu, existen suficientes motivos para mantener la paternidad del que sin duda alguna la reconoció, ha cubierto sus necesidades, y le ha brindado el afecto y cariño necesarios para su desarrollo (...)”. 


\subsubsection{El ejercicio conjunto de la acción por el hijo y la persona que se considere tener el derecho de reconocer al hijo. El litisconsorcio activo necesario}

Ergo, valorada por el Tribunal la conveniencia de seguir o no la sustanciación del proceso, decisión en la cual, no niego que tiene un peso significativo el dictamen del fiscal, si bien no es concluyente, si se inclina por una decisión positiva, se continuarán los trámites del proceso, dándose traslado de la demanda a los demandados y, de ser negativa, se acordará el archivo de las actuaciones, reservándole a las partes el derecho para que lo ejerzan una vez que el menor haya arribado a la mayoría de edad. En tal caso, sí que será necesario un litisconsorcio activo, esto es, que la acción sea ejercitada conjuntamente por quien se considere con derecho a reclamar la paternidad o la maternidad e impugnar la filiación existente, que no es el derecho a reconocer, como indebidamente alude el legislador en el último párrafo in fine del artículo 81 del Código de Familia y por el hijo en relación con el cual se pretende reclamar filiación. Fórmula legal que no deja de tener inconvenientes, en tanto complejiza el éxito del proceso al exigir la constitución de un litisconsorcio activo necesario. Para algunos estudiosos de la materia en Cuba, debiera permitirse el ejercicio de la acción por quien se considere padre o madre del hijo y demandar a este, de modo que si el hijo se opone a la demanda de impugnación de filiación y reclamación de paternidad, se debieran archivar las actuaciones ${ }^{35}$. Empero, al estudiarse con detenimiento el fenómeno no podemos negar que, al ejercitarse una acción mixta encaminada a impugnar una filiación legalmente determinada en la que intervino un tercero, con el "consentimiento" del otro progenitor del hijo y a la vez destinada a que se rectifique la filiación y se acceda a la reclamación de filiación, el hijo sería parte actora del proceso y no parte demandada, pues la acción no se ejercita en su contra, ya que no fue él quien intervino en los actos de reconocimiento de filiación recogidos en el asiento de inscripción de su nacimiento. El litisconsorcio tiene su razón de ser en que son dos los que sostienen la acción de reclamación, el padre o la madre que se cree en el derecho de reconocer al hijo y el propio hijo interesado en que se rectifique su filiación, al resultar este mayor de edad. Con ello se garantiza además implícitamente el "consentimiento" del hijo, que es necesario incluso para el acto de reconocimiento voluntario de la filiación. El hijo en los juicios filiatorios nunca sería parte demandada, en todo caso parte actora.

\subsubsection{Imprescriptibilidad de la acción. La posición contraria del Tribunal Supremo}

Otro tópico no menos polémico, es el de la prescripción o caducidad de la acción reclamatoria de la filiación. Parto de la tesis de que el artículo 81 del Código de Familia re-

35 Con tal parecer, AldAYA BAYÓN, Rita, op. cit. (n. 12), p. 71. 
gula la acción mixta de impugnación y reclamación de filiación la que por su naturaleza es imprescriptible y ello puede colegirse de lo regulado en el primer párrafo in fine de dicho precepto al establecer que dicha acción podrá ser establecida "en cualquier tiempo", sinónimo de imprescriptibilidad. Lamentablemente, esta no ha sido la interpretación del Alto Foro que vincula indebidamente los artículos 80 y 81 del mencionado texto legal, cuando el primero de ellos regula la acción de impugnación y el segundo la de reclamación de filiación que, en ese supuesto concreto, lleva implícita la de impugnación. Para el Supremo Tribunal, no hay distingos entre una y otra acción, los valores de la justicia y de la equidad llevan a que se aplique a la acción contenida en el artículo 81 el mismo plazo de caducidad que para la acción impugnatoria que reserva el artículo 80 del Código de Familia, obviando que en el último caso el hijo, ya mayor de edad, lo que pretende es que se niegue por vía judicial esa filiación, pero no busca la identidad filiatoria, o sea, no entabla acción de reclamación de paternidad, sino únicamente de impugnación de la filiación existente. Empero, para el Alto Foro según tesis sostenida en la Sentencia No. 631, de 31 de julio de 1996:

“ (...) lo previsto en el último párrafo del artículo 81 del Código de Familia, no puede interpretarse aisladamente a lo preceptuado en el artículo 80 del propio cuerpo legal, habida cuenta que el hecho de que resulte obligado para quien se considere con derecho a reconocer a un hijo inscripto por otro, cuando éste fuera mayor de edad, a efectuar la acción impugnatoria de conjunto con el mismo, en modo alguno puede ser excluyente del plazo de caducidad que expresamente determina el citado artículo 80, pues esta interpretación conllevaría ofrecer mayor garantía a un presunto padre, hasta ese momento desconocido, que al propio hijo afectado, de entenderse que en cualquier tiempo podrá establecer la acción, y es por ello, que, sabiamente, el legislador en estos casos obliga a su ejercicio de conjunto, ya que al encontrarse el hijo reconocido durante su minoría de edad obligado a impugnar ese reconocimiento dentro del año siguiente a la fecha en que arribó a su mayoría de edad, tácitamente se exige al otro actor a cumplir también ese plazo; que en el caso cuestionado se ejerció la acción cuando la hija, cuyo reconocimiento se pretende, contaba con 34 años de edad, por lo que de conformidad a lo establecido en los artículos 125 y 126 del Código Civil fuerza declarar de oficio la caducidad del reclamado derecho por ambos pretendidos y se desestima in integrum el recurso(...)”

Criterio que sigue siendo abrazado por el propio Tribunal, prueba de la cual lo es la reciente Sentencia No. 422 de 18 de diciembre del 2008, único Considerando (ponente González García) a cuyo tenor:

“(...) los aludidos preceptos (artículos 80 y 81) han de interpretarse de manera complementaria y no excluyente, pues regulan el ejercicio de acciones de similar naturaleza 
impugnatoria de la filiación, pero en cada una de ellas son diferentes los sujetos que las materializan; a saber: en el primero el hijo reconocido durante su minoría de edad que decide impugnar la paternidad de quien a su juicio no resulta ser su verdadero progenitor una vez alcanzada la mayoría de edad, sin que necesariamente deba señalar y demandar a quien resulte su verdadero padre, aun cuando pudiera ejercitar ambas acciones conjuntamente de así decidirlo; acción que está acotada en el tiempo por el perentorio plazo de caducidad de un año contado a partir del arribo a su mayoría de edad; y la ejercitada en el presente, consagrada en el artículo ochenta y uno del Código de Familia, concurrente en el padre biológico que conjuntamente con su hijo ya mayor de edad reclaman tal condición filial, y con independencia de que dicho precepto genéricamente la declara no caducable, también en su párrafo final la supedita, en el supuesto bajo examen, a su ejercicio conjunto por padre e hijo, circunstancia que de hecho en ese específico caso le priva del mencionado carácter; pues no puede sustraerse el segundo de dichos sujetos del plazo de caducidad que le fija el artículo ochenta, plazo en el que únicamente sería posible el ejercicio conjunto de la acción impugnatoria; y en el subjudice la hija cuyo reconocimiento se pretende cuenta con veintitrés años de edad, habiendo decursado en exceso el aludido plazo de caducidad del derecho reclamado, apreciable de oficio y no susceptible de interrupción ni suspensión por causa alguna, conforme señalan los artículos ciento veinticinco y ciento veintiséis del Código Civil (...)”.

Por último, de la Sentencia No. 153 de 29 de mayo de 2009, único Considerando (ponente Carrasco Casi), cabría también colegir el criterio del Alto Foro de considerar caducable el derecho del progenitor a ejercitar la acción mixta de impugnación y reclamación de filiación, al declarar sin lugar el recurso de casación establecido por el progenitor que intentaba el ejercicio de la mencionada acción, conjuntamente con el hijo, decursado el plazo de un año. El recurso se sustentaba al amparo del artículo 630.1 de la LPCALE, acusando como infringidos los artículos 37 de la Constitución y 77 y 81 del Código de Familia y aduciéndose como concepto de la infracción el que:

“(...) no puede caducar jamás el derecho de aquel progenitor a quien la Ley autoriza la validez de su acción en cualquier tiempo y siempre que el fin perseguido sea inscribir como suyo el hijo reconocido previamente por otro (...), y, no resulta lógico interpretar que el derecho que enerve al hijo en su acción por haber transcurrido un año posterior al arribar a la mayoría de edad tenga que irradiarse y fundirse en perjuicio del progenitor".

Para el Tribunal Supremo, la excepcionalidad del plazo de caducidad concedido al hijo para impugnar su filiación paterna o materna (artículo 80 del Código de Familia): 
“(...) se encuentra igualmente cuando la acción es del presunto padre que debe ejercitarse con él cuando se trata de una persona mayor de edad, sin que el alcance de la interpretación de los artículos ochenta y ochenta y uno del mencionada Código, quebrante los principios que sobre la materia consagra la Constitución (...)”.

\subsubsection{La exclusión del derecho a suceder a los hijos, del progenitor cuya paternidad o maternidad haya sido determinada judicialmente contra su oposición}

El éxito en el ejercicio de las acciones reclamatorias de filiación conducirán a la determinación por sentencia firme del Tribunal competente de la filiación, de modo que conforme con el artículo 40 e) de la Ley del Registro del Estado Civil, el oficial a cargo de este, practicará en atención a la ejecutoria judicial, el asiento de inscripción. Empero, nada se regula en nuestro ordenamiento sustantivo, esencialmente sucesorio, entiéndase Código Civil, en relación con los efectos que ello pudiera tener en sede sucesoria para evitar la paradoja de que el progenitor cuya paternidad o maternidad haya sido determinada de esta manera, con total oposición de su parte, pueda, en caso de fallecimiento del hijo, concurrir a su sucesión ab intestato (vid. artículos 510 y 514 del Código Civil). A modo de ejemplo, vale la pena tomar como referencia la fórmula legal consagrada en el artículo 111 del vigente Código Civil español que excluye de la sucesión de los hijos al progenitor cuando, entre otras razones "(...) la filiación haya sido judicialmente determinada contra su oposición”. Obsérvese que el legislador no le da el tratamiento de indignidad sucesoria, razón por la cual no se requeriría de probanza judicial, sino, sería suficiente estar incurso en tal circunstancia para que automáticamente se le excluya de la sucesión, a menos que, tal veto legal se alce por: "determinación del representante legal del hijo aprobada judicialmente o por voluntad del propio hijo una vez alcanzada la plena capacidad”. Para Quicios Molina, quien ha intervenido en los últimos comentarios al Código Civil español, bajo la dirección del profesor Bercovitz Rodríguez-Cano, en su condición de ponente del citado artículo, procede, entre otros supuestos que no vienen al caso mencionar en esta oportunidad, cuando la filiación haya sido derivada de sentencia civil firme, habiéndose opuesto a dicha determinación el progenitor o, incluso manteniendo una actitud negativa durante la tramitación del procedimiento. Se trata de una sanción que opera automáticamente, aun no siendo necesaria la petición de parte ni el pronunciamiento judicial ${ }^{36}$. Cabría meditar en este sentido, si merece la incorporación de esta figura, con tratamiento disímil al que tradicionalmente se le ha venido ofreciendo a las causales de indignidad sucesoria en nuestro ordenamiento jurídico, si se toma en cuenta además, el número cada vez más creciente de procesos judiciales en los que se ejercitan acciones reclamatorias de filiación

36 Quicios Molina, Susana. "Comentarios al artículo 111”. En: Comentarios al Código Civil. BerCovitz RodríGuezCANO, Rodrigo (Coordinador) -2a edición- Madrid, España: Thomson-Aranzadi, 2006, pp. 248-250. 
contra progenitores que a toda costa niegan la paternidad, absteniéndose incluso de concurrir a la práctica de las pruebas hematológicas a los fines de determinar el $\mathrm{ADN}$ ¿Sería justo que quien incurra en tal conducta, por un azar de la vida suceda luego al menor hijo, cuya filiación fue impuesta en contra de su propia voluntad? De todas formas, la posición normativa que se adopte en todo caso, debiera dar cabida a excepciones, ya sea por la propia voluntad del hijo al arribar a la edad permisiva para testar, o incluso antes, a través de su representante legal, previa aprobación judicial. Lo importante es que el referente en el Derecho Comparado ya existe.

\subsection{LA ACCIONES DE IMPUGNACIÓN DE LA PATERNIDAD O DE LA MATERNIDAD}

Su finalidad es destruir una filiación formalmente existente, para lo cual se pretende acercar la verdad jurídica a la verdad biológica. Siguiendo la clasificación de Rodríguez Corría ${ }^{37}$, dentro de ellas cabe ubicar:

(a)La acción prevista en el artículo 78 del Código de Familia, a cuyo tenor se impugna la filiación matrimonial, intentándose destruir las presunciones filiatorias reconocidas en el artículo 74 del Código de Familia.

En efecto, cuando el funcionario a cargo del Registro del Estado Civil practica el asiento de inscripción del nacimiento sobre la base de la declaración que hace uno de los cónyuges, tal declaración se expande en cuanto a sus efectos filiatorios para el otro, como resultado de la aplicación de cualquiera de las presunciones contenidas en el artículo 74, circunstancia que se hace extensiva a los supuestos de matrimonios o uniones de hecho putativas. Para el artículo 45 de la Ley del Registro del Estado Civil, será suficiente la presencia de uno de los padres, de tal manera que los apellidos quedarían dispuestos en la manera que prevé el precepto, en su tradición machista de que primero sería el apellido paterno y luego el materno, pero el propio artículo deja expedita la vía de la impugnación, que en relación directa con él, establece el artículo 78 del Código de Familia. Legitimado al efecto solo estará el cónyuge que no concurrió ante el oficial encargado del Registro del Estado Civil y el motivo de la impugnación lo reduce el legislador en el propio precepto a "la imposibilidad de los cónyuges para haber procreado el hijo". Vuelvo a recalcar que lo que se impugna es la filiación, no el acto de reconocimiento, no la declaración de voluntad del otro progenitor. La prueba de tal imposibilidad tiene que versar sobre el hecho de que no hayan tenido lugar las relaciones sexuales entre los miembros de la pareja, sin que, a diferencia de otras legislaciones, se fije un plazo, de manera que demostrada la imposibilidad física del acceso carnal durante él, quepa la destrucción de la filiación matrimonial. No obstante, hoy día no queda reducida la destrucción

37 Rodríguez CORRÍA, Reinerio, op. cit. (n. 31), pp. 7 y ss. 
de las presunciones de filiación matrimonial, a dicha imposibilidad física de cohabitación marital, cabría demostrar también con la aplicación de las pruebas genéticas u otras pruebas biológicas la impotencia generandi (o imposibilidad biológica para la procreación), particular que destruiría también la presunción iuris tantum de paternidad y, en consecuencia, permitiría dar al traste con la paternidad formal determinada conforme con la presunción filiatoria del artículo 74.1 del Código de Familia. Acción que está supeditada a un plazo de caducidad de seis meses (ex artículo 79 del Código de Familia) para cuyo cómputo, el die a quo se hace coincidir con el día siguiente a aquel en que el titular de la acción tuvo conocimiento del asiento de inscripción practicado por el oficial del Registro del Estado Civil, en su ausencia, a instancia de su cónyuge, quien declaró el nacimiento del hijo habido dentro del matrimonio, plazo a mi juicio, demasiado perentorio, si bien la manera en que se fija el die a quo no resulta demasiado lesiva para el titular de la acción impugnatoria.

(b) La acción prevista en el artículo 48, segundo párrafo de la Ley del Registro del Estado Civil a cuyo tenor cabría impugnar las presunciones de filiación extramatrimonial consagradas en el artículo 75, para la paternidad, como resultado de la no concurrencia ante el oficial encargado del Registro del Estado Civil del padre, que citado, no concurre en el plazo de noventa días previsto por la ley a negar la paternidad, supuesto en el que dicho comportamiento se entiende como un reconocimiento tácito de paternidad. En tal caso, el plazo de caducidad no es de seis meses, sino de un año, lo que no tiene justificación desde una posición lógica. Tanto una norma como la otra, forman parte del subsistema jurídico regulatorio de la filiación. No hay motivo para que la acción reconocida en el artículo 78 del Código de Familia, caduque a los seis meses y esta al año, si ambas son acciones impugnatorias, por ello resulta muy atinente la fórmula empleada en el artículo 94 del Anteproyecto de Código de Familia que tiende a la unificación del plazo de caducidad, situándolo en un año, lo que por demás resulta más adecuado en pos de la búsqueda de la verdad material.

(c) Por último, cabe mencionar la acción reconocida en el artículo 80, tantas veces confundida con la regulada en el artículo 81, ambos del Código de Familia, atribuible al hijo y encaminada a la impugnación de la filiación, no del reconocimiento. Su finalidad es rectificar la filiación, reconocida por un tercero, en relación con la cual el hijo demostrará su no coincidencia con el dato biológico. Si tiene éxito en el ejercicio de esa acción, quedará con una sola filiación, asumiendo los dos apellidos del progenitor contra el cual no ejercita la acción impugnatoria de filiación. Para el ejercicio de dicha acción, solo está legitimado el hijo, reconocido durante su minoridad, precisamente por eso.

Si algo ha sido controvertido en ella, es el cómputo del plazo de caducidad, el que se sitúa en el año, eso sí, automáticamente desde el día después a aquel en que arribó a la mayoría de edad, lo cual no coincide con el pleno ejercicio de su capacidad jurídica, si, conforme con lo dispuesto en el artículo 3 del Código de Familia, se trata de una mujer de 14 años o de un hombre de 16 años, que fueren autorizados para formalizar matrimonio. En tal supuesto, 
según el dictado del artículo 29.1 b) del Código Civil, han alcanzado la plena capacidad jurídica, sin haber arribado a la mayoría de edad, pero como son plenamente capaces, podrían ejercitar cualquier acción de la que son titulares, entre ellas, la de impugnación de la filiación, la que, lamentablemente siguiendo la expresión literal del artículo 81, se supedita a arribar a la mayoría de edad. Igualmente se le objeta, que, a diferencia de la acción anteriormente mencionada, el die a quo para el cómputo del plazo de caducidad no se hace depender de un hecho, de matiz más subjetivo, pero más justo, como lo es el conocimiento por parte del titular de la circunstancia que da lugar al ejercicio de la acción $(v . g r$., que la persona que le reconoció no es su verdadero padre), lo que, como afirma Rodríguez Corría, puede tener lugar después que el hijo haya arribado a la mayoría de edad ${ }^{38}$.

En relación con la transmisibilidad mortis causa de estas acciones de impugnación de la filiación reitero lo ya dicho con motivo de las acciones reclamativas de filiación. Heredero no es sinónimo de pariente allegado al causante, que quizás esté más interesado en investigar la paternidad o maternidad o en impugnar una paternidad o maternidad formalmente determinada, con asiento en el registro correspondiente ${ }^{39}$, aun cuando reconozco que tradicionalmente los legisladores, con cautela, han legitimado a los herederos para la continuación de su ejercicio, cuanto el titular ha fallecido después de iniciado el proceso judicial, o con extrema prudencia cuando aún no lo ha hecho, concediendo a tal fin un plazo reducido de caducidad. No obstante, no debe olvidarse que el reconocer la transmisión de la acción iure hereditario, pudiera privar a un pariente allegado del titular, dígase $v$. gr., un hijo, de su ejercicio, si el titular de la acción nombró heredero voluntario a un extraño. Por esa razón, considero más atinado una transmisión ope legis de la acción a los parientes más propincuos del titular. Sobre el tema, los autores del Anteproyecto de Código de Familia en los artículos del 91 al 97 hacen mutis. ¿Significa ello que su ejercicio expira con la muerte de su titular? ¿No habría otro interés legítimo que atender? Si la respuesta cabe encontrarla en la formulación del artículo 95, a cuyo tenor: "Pueden impugnar el reconocimiento los terceros que invoquen un interés legitimo",

\footnotetext{
38 Rodríguez Corría, Reinerio, op. cit. (n. 31), pp. 13-14. El propio autor valora como el Anteproyecto de Código de Familia en su artículo 97 rectifica esta posición, haciendo extensivo además, el ejercicio de dicha acción a los menores e incapacitados judicialmente, eso sí, con total inmediatez, de modo que sus representantes legales o el fiscal deberán ejercitar la acción sin esperar a que arriben a la mayoría de edad. Ergo, a mi juicio, si la ejercitan en este período, sin éxito, no podrán ejercitarla cuando tengan dicha mayoría de edad. Llama la atención también que el mencionado artículo 97, expresamente nada regula sobre el plazo de caducidad de un año que dispensa para el resto de las acciones comprendidas en los artículos 91, 92 y 93, en las que están legitimados los progenitores.

39 Máxime en el caso de Cuba en que el testador tiene más libertad de testar que en otros ordenamientos jurídicos pues para atribuirse la condición de legitimario hay que demostrar no solo el vínculo parental o conyugal con el causante, sino las conditio iuris de dependencia económica respecto de él y la inaptitud para trabajar (artículo 492 y 493 del Código Civil). No se olvide tampoco que el testamento tiene una gran incidencia en la sociedad cubana, por ser una figura bien recurrida, el acto dispositivo patrimonial por causa de muerte por excelencia, y no siempre los herederos instituidos coinciden con los parientes a los que un conflicto filiatorio pudiera resultarle de mayor interés. Sobre este tema, PÉrEZ Gallardo, Leonardo B., "El Derecho de Sucesiones en cifras. Recapitulación y pronósticos”. En: El Derecho de Sucesiones en Iberoamérica. Tensiones y retos, Bogotá, Colombia: Temis; México: Ubijus; Madrid, España: Reus; Buenos Aires, Argentina: Zavalia, 2009, pp. 327-334.
} 
no creo que se haya pensado en esta situación comentada en la manera en que se formula por la norma legal. En primer orden, porque si el sentido es atribuirla a los herederos, estos nunca serán terceros, pues como herederos al fin, se subrogan en todos los derechos, bienes $\mathrm{y}$ acciones de los cuales era titular su causante, constituyendo su alter ego, no un tercero ${ }^{40}$. Tampoco creo que los hijos del titular sean terceros, sin más. A ellos, en principio, no va dirigida la norma, si bien, en ausencia de una norma ad hoc, y a los efectos de solventar el posible vacío normativo, pudieran invocarla para ejercitar la acción impugnatoria, demostrado en vía judicial su innegable interés legítimo en el ejercicio de esta acción, impedida de ejercitar por su padre o por su madre, al sobrevenirle a uno a otro la muerte.

\subsection{LA ACCIÓN DE IMPUTACIÓN DE LA PATERNIDAD O DE LA MATERNIDAD STRICTO SENSU}

Quizás lo más interesante, motivado por su relativa novedad, en la regulación de las acciones filiatorias, sea la acción de imputación, que tiene su sede solo en vía registral en los artículos 48 y 53 de la Ley, y en los artículos 81 y 83 de su Reglamento. Y lo digo, porque rompe esquemas tradicionales, ello en función de la búsqueda de la filiación paterna del hijo. Nada empece para que la madre o el padre revelen la identidad del otro presunto progenitor de su hijo, sea aquel casado o no. En una jurisprudencia de intereses, es un bien primordialmente atendible la protección legal de la identidad filiatoria del menor, sobre los derechos a la intimidad y la vida privada de los progenitores. Suficiente que la madre o el padre imputen la paternidad o maternidad según el caso, esto es, atribuyan la autoría del hijo a una persona, para que entonces sea citada oficialmente por el registrador a cargo del Registro del Estado Civil, a los fines de que, en el improrrogable plazo de noventa días, acepte o niegue la paternidad o la maternidad. De no concurrir, se entenderá tácitamente que acepta dicha paternidad o maternidad y se inscribirá al hijo como suyo, asumiendo el apellido paterno o el materno, según sea el caso. Técnicamente, en el orden procesal, no la reconozco como acción. En buena medida es un derecho o facultad atribuida ex lege a favor de la madre o del padre que se ejercita en sede registral. Y tal es la preocupación del legislador, que si con los datos que aporta la madre o el padre, no se puede citar al presunto padre o a la presunta madre respectivamente, se le concede un nuevo plazo para que pueda aportar esos nuevos datos y solo cuando sea imputable a quien declaró la maternidad o la paternidad, la imposibilidad de citar y apercibir personalmente al otro progenitor, es que se practicará la inscripción por el funcionario registral, sin consignar los datos de ese progenitor o progenitora (vid. artículo 53 de la Ley del Registro del Estado Civil).

\footnotetext{
40 Con razón se ha dicho por la Sala de lo Civil y de lo Administrativo en su Sentencia No. 320 de 16 de mayo del 2005, segundo Considerando (ponente Acosta Ricart) que: “(...) se llama causahabiente a la persona que sucede a otra en sus derechos u obligaciones o ambas, o que adquiere una cosa de otra, pero el concepto de causahabiente como el de sucesión en derechos implica la preexistencia del derecho, mientras que el heredero es la persona que por testamento o por ley sucede a título universal en todo o en parte de la herencia (...)".
} 
La imputación solo se admite en supuestos de hijos habidos en uniones extramatrimoniales, pues la ley no habilita tal posibilidad cuando el hijo es habido del matrimonio en razón de las presunciones filiatorias que recaen sobre el otro cónyuge del declarante de su paternidad o maternidad. Es dable aclarar que la imputación está implícita en la propia acción de reclamación de paternidad o maternidad, por ello me he referido a la imputación stricto sensu. Cuando se reclama la paternidad o la maternidad en relación con una persona, se le está imputando la autoría en la procreación del hijo.

Por fortuna, también en aras de sistematizar las acciones filiatorias, el Anteproyecto de Código de Familia, le da la cobertura legal de la cual hoy carece, al estar reconocida tan solo en vía registral. El autor de la norma prevé su entronización con las normas registrales a las cuales remite en su artículo 98, resultando criticable que, a diferencia de lo previsto en el artículo 53, último párrafo de la Ley del Registro del Estado Civil, limite el derecho de imputación únicamente a la madre, cuando ello pudiera ser posible, si bien en Cuba resultaría excepcional, en el supuesto de que sea el hombre el que hubiera declarado la paternidad y pretendiese imputar la maternidad a quien considerare es la madre del hijo. Eso sí, se mantiene la tendencia de que solo es posible la imputación en sede extramatrimonial por los efectos de las presunciones filiatorias dentro del matrimonio formalizado o judicialmente reconocido.

\section{TÍTULO Y PRUEBA DEL ESTADO FILIATORIO}

Debe quedar bien delimitado, tal y como se ha explicado con detenimiento que, en nuestro ordenamiento jurídico los modos de determinación de la filiación son: el reconocimiento del hijo, las presunciones y la sentencia judicial firme que resuelve los litigios filiatorios en supuestos de reclamación de paternidad o de maternidad.

Ahora bien, según el Derecho vigente, título de legitimación, o sea, el hecho o acto que posibilita estimar determinada una filiación en la esfera jurídica, independientemente de que coincida o no con la verdad, formalidad exigida que manifiesta la filiación, sin el cual no pueden ser ejercidos los derechos y deberes que emanan de la filiación, se reduce al asiento de inscripción del nacimiento en el Registro del Estado Civil, según se colige de lo dispuesto en el artículo 3 de la Ley del Registro del Estado Civil. Las certificaciones que sobre la base de ese asiento expide el registrador son prueba de la filiación paterna o materna, solo destruible a través del proceso judicial correspondiente (vid. artículo 55 de la propia Ley). No obstante, no es diáfano el legislador cuando al referirse al título de legitimación continuamente hace referencia al efecto probatorio del mismo. Cabe aclarar que más que modo probatorio de la filiación, él es título que acredita con eficacia erga omnes la filiación misma. No es dable confundirlo tampoco con los títulos de atribución o adquisición que tienen una naturaleza supletoria respecto de este al constituir el basamento de la fijación de la filiación. 
A la luz del ordenamiento jurídico cubano, la posesión de estado es un elemento probatorio, como lo puede ser la notoriedad de las relaciones maritales existentes entre los padres al período en que tuvo lugar la concepción, el documento indubitado en el que consta la declaración del padre, de la cual cabe inferir su paternidad, que será aportado como hecho base, para colegir el hecho deducido de la presunción filiatoria, según lo dispuesto en el artículo 75 del Código de Familia en relación con el artículo 350 de la LPCALE.

La prueba de la filiación materna lo constituye el hecho del parto y la identidad del hijo y de la filiación habida dentro del matrimonio el asiento mismo de inscripción del matrimonio de los padres. Ello, amén de todas las pruebas biológicas que se practiquen a los fines de esclarecer la verdadera identidad paterna o materna del hijo.

\section{LA FILIACIÓN INDUCIDA: OMISIÓN PERENNE EN EL DERECHO FAMILIAR CUBANO}

Otra de las orfandades normativas en sede de filiación es lo relativo a la reproducción humana asistida. A muy lamentar, no existe en Cuba norma alguna en el orden legal, tuitiva de la aplicación de técnicas de reproducción humana asistida, las que desde hace más de dos décadas se practican, con éxito, en Cuba. Es verdaderamente insólito que en un país como Cuba que va a la cabeza en avances de las ciencias médicas en el continente, exista una total ausencia del más mínimo resquicio de regulación jurídica en este orden ${ }^{41}$. Las técnicas de reproducción humana asistida, ya no constituyen novedad ni en el orden médico ni en el jurídico. A pesar de todo lo que se ha escrito en los últimos años por la doctrina jurídica y de la necesidad de que este proceder médico esté dotado de seguridad jurídica, que se reconozca el derecho del anonimato del dador, pero que a su vez se compatibilice con el derecho que tiene el hijo procreado por estas técnicas de conocer su verdadera identidad, cuando el material genético es aportado por un tercero, distinto a su padre o a su madre legal, así como todo lo referente al consentimiento informado del dador y del padre procreacional, no se ha hecho el más mínimo intento por dotar de una norma jurídica, a un proceder médico que ha cambiado desde hace más de tres décadas los postulados tradicionales en los que se ha sustentado la filiación.

La única nave que se divisa en el horizonte es el Anteproyecto de Código de Familia, el cual pretende dar fugaces destellos de luz al incluir en su preceptiva dos preceptos relativos al tema, uno de alcance sumamente general (artículo 108), a cuyo tenor se dispone que la filiación resultante de la aplicación de las técnicas de reproducción asistida se regirá por las

41 Rosabal lam, Carmen, op. cit. (n. 7), pp. 120-123. 
normas del Código de Familia y las de la Ley del Registro del Estado Civil, lo cual sin dudas es acertado, pero no hace más que llevar a la norma legal lo que hoy es una realidad palpable. No es otra cosa que marear a la perdiz, pero sin éxito en la caza. A pesar de la parquedad y la parvedad de la regulación jurídica de la filiación, el vigente Código de Familia ha sido el que ha cobijado la aplicación de las técnicas de reproducción humana asistida en Cuba. La filiación de los nacidos como consecuencia del éxito de su aplicación ha tenido la cobertura legal que hoy ofrecen las escasas normas de nuestro vetusto Código de Familia y de la Ley del Registro del Estado Civil. Esperar entonces tantos años para que el nuevo Código de Familia, de aprobarse, diga lo mismo, no creo que suponga adelantar mucho trecho. Se está a la espera que el Ministerio de Salud Pública dicte una resolución a tal efecto, pero ¿con una resolución administrativa se solucionaría todo el vacío legislativo que existe en este orden? Hay principios que deben regularse en una norma sobre técnicas de reproducción asistida que por su alcance y su dimensión ética y ontológica riñen per se con una norma jurídica de la jerarquía de una mera resolución administrativa, dictada por un ministro del ramo.

El otro de los preceptos propuestos a modo de lege ferenda (artículo 109) que sería el único que entraría a regular un problema de fondo que pudiera generar la aplicación de estas técnicas en supuestos de intervención de un tercero, ajeno a la pareja, como dador del material genético, en primer orden deja implícitamente regulado que el acceso a estas técnicas se limita a la pareja, ya sea de matrimonio formalmente constituido o de unión factual y que el tercero dador será con exclusividad el hombre, dador de semen. Tratándose de la aplicación de las técnicas se supone que se deje constancia por escrito del consentimiento informado de la pareja (lo cual omite el precepto), a cuyo tenor el padre procreacional o padre legal admite la inseminación o la práctica de la fertilización in vitro con el óvulo que aportará su pareja, creando una expectativa o confianza que no puede desdecir a través del ejercicio de la acción impugnatoria de su paternidad, ni tampoco le sería dable a la madre ejercitar contra el dador, padre genético de su hijo, pero no padre procreacional o padre legal, la acción reclamatoria de filiación, quien estaría amparado por el principio del anonimato (en ambos casos se erige también la barrera infranqueable de la prohibición del venire contra factum proprium). El propio precepto veda el ejercicio de estas acciones filiatorias, tanto al padre como a la madre legal. De modo que, si se someten a la aplicación de las técnicas, tendrán que asumir las consecuencias del éxito de su aplicación y con ello asumir ambos los efectos que la relación jurídica filiatoria lleva implícito, aunque no exista identidad entre el dato biológico y el efecto jurídico. Aun casados, no serían de aplicación las presunciones filiatorias reguladas a tal fin (en el Anteproyecto en el artículo 88), pues el consentimiento informado lleva implícito un reconocimiento filiatorio anticipado.

No obstante, en el segundo párrafo del mencionado artículo se admite, aun con carácter excepcional, la posibilidad de impugnar la filiación cuando se justifique, tras la práctica 
de las pruebas genéticas correspondientes, que el material genético empleado pertenece a un tercero, y no al miembro masculino de la pareja. Impugnación para la que estaría legitimado el padre legal.

Todos los demás dilemas jurídicos que la aplicación de las técnicas en estas tres décadas ha generado no solo en Cuba sino en todos los países que la han utilizado como vía de asistir la procreación humana, quedarían a la expectación de una norma ad hoc para la cual habría entonces que seguir esperando, más aún de lo que hemos aguardado por el Código de Familia. Mientras tanto, las ciencias y las tecnologías avanzan vertiginosamente, sin que, en nuestro caso, el Derecho pueda acompasar los designios que la genética, la biología, la medicina, la bioética, pautan a la humanidad.

\section{REFERENCIAS BIBLIOGRÁFICAS}

Aldaya BAYÓn, Rita María. El régimen jurídico de la fliación (Tesis de maestría en Derecho de Familia).Habana, Cuba: Facultad de Derecho, Universidad de La Habana, 2007.

Álvarez TORres, Osvaldo, "El procedimiento familiar en Cuba. Una necesidad impostergable”, en Revista Cubana de Derecho, UNJC. Cuba, Habana: Ediciones Cubanas, No. 18, julio-diciembre, 2001.

Ávila Álvarez, Pedro. Derecho Notarial. -7ª edición- Barcelona, España: Bosch, 1990.

CÓDIGO CIVIL DE LA REPÚBLICA DE CUBA, Ley No. 59/1987 de 16 de julio, anotado y concordado con los ordenamientos cubano y español por Ángel Acedo Penco y Leonardo B. Pérez Gallardo, Dykinson, Madrid, 2005.

CÓDIGO DE FAMILIA (anotado y concordado), 2a edición, Divulgación, Ministerio de Justicia, La Habana, 1987; Ley No. 7/1977 de 19 de agosto, Editorial Pueblo y Educación, 1a reimpresión, La Habana, 1983, modificada por el Decreto-Ley No. 241/2006 de 26 de septiembre en Gaceta Oficial de la República de Cuba, Extraordinaria, No. 33, de 27 de septiembre del 2006.

Gómez Treto, Raúl, “¿Hacia un nuevo Código de Familia?”, en Revista Cubana de Derecho, No. 29, UNJC. Cuba, Habana: Ediciones Cubanas. Enero-junio 2007.

GuZMÁn Ávalos, Aníbal. La filiación en los umbrales del siglo XXI. D.F., México: Porrúa, 2005.

LEY No. 51/1985 de 15 de julio, Del Registro del Estado Civil, publicación del MINJUS, La Habana, 1998 y su Reglamento contenido en la Resolución No. 157/1985 de 25 de diciembre del Ministro de Justicia, publicación del MINJUS, La Habana, 1998.

LEY DE LAS NOTARÍAs ESTATALES, Ley No. 50/1984 de 28 de diciembre, editada por el Ministerio de Justicia, mayo de 1986 y su Reglamento contenido en la Resolución No. 70/1992 de 9 de junio del Ministro de Justicia.

Martínez Giralt, Félix, Sucesiones (copia de clases). La Habana, Cuba: Facultad de Derecho, Universidad de La Habana, Curso 1945-46.

Mesa Castillo, Olga. "Regulación normativa de la filiación en el Estado cubano”. En: Temas de Derecho de Familia, La Habana, Cuba: Colectivo de autores, Félix Varela, 2001.

"La formalización del matrimonio ante notario y registrador del estado civil". En: Derecho Notarial, tomo III, Leonardo B. Pérez Gallardo e Isidoro Lora-Tamayo Rodríguez (coordinadores). La Habana, Cuba: Félix Varela, 2008.

Derecho de Familia, Módulo 2 -El matrimonio, VI Parte- Nulidad del matrimonio. La Habana, Cuba: Félix Varela, 2005. 
OJEDA RODRÍGUEZ, Nancy de la C. El reconocimiento de hijos y la función notarial. Conferencia dictada en la VII Jornada Internacional del Notariado cubano, celebrada en La Habana, del 29 al 31 de mayo del 2008 (inédita),

PARra BeníteZ, Jorge. La filiación en Derecho de Familia. Bogotá, Colombia: Leyer 2008.

PÉREZ GALlardo, Leonardo B. "La declaración judicial de presunción de muerte: una aproximación tópica a su estudio", en La regulación jurídica de la muerte en Iberoamérica, con particular referencia al Derecho cubano, Bogotá, Colombia: Temis; México: Ubijus; Madrid, España: Reus; Buenos Aires, Argentina: Zavalia, 2009.

"El Derecho de Sucesiones en cifras. Recapitulación y pronósticos”. En: El Derecho de Sucesiones en Iberoamérica. Tensiones y retos, Bogotá, Colombia: Temis; México: Ubijus; Madrid, España: Reus; Buenos Aires, Argentina: Zavalia, 2009.

Quicios Molina, Susana, "Comentarios al artículo 111”, en Comentarios al Código Civil, Rodrigo Bercovitz Rodríguez-Cano (Coordinador) -2a edición- Madrid, España: Thomson-Aranzadi, 2006.

Rivero Hernández, Francisco. Elementos de Derecho Civil IV - Derecho de Familia. Volumen $2^{\circ}-3^{\mathrm{a}}$ edición-, Barcelona, España: Bosch, 1989.

RODRÍGUEZ CORRÍA, Reinerio. "La fliación y sus acciones. Algunas reflexiones sobre su regulación y aplicación práctica" (inédito).

Rosabal Lam, Carmen. Disquisiciones teóricas en torno a la filiación en Cuba. Memoria de prueba (diplomado) profesora guía Dra. Olga Mesa Castillo. La Habana, Cuba: Facultad de Derecho, Universidad de La Habana, 2000 .

VALDÉs DíAZ, Caridad del C. “Comentarios al artículo 29”, en Comentarios al Código Civil cubano, tomo I - Libro I Disposiciones preliminares. Relación jurídica, Leonardo B. Pérez Gallardo (director) (en edición).

ZaCCARIA, Alessio. Diritti extrapatrimoniali e successione. Cedam, Padova, 1998.

ZaVAlA, Gastón A. Declaratoria extrajudicial de herederos. La intervención notarial. Buenos Aires, Argentina: Ad Hoc, 2007. 